Journal of Sea Research

September 2017, Volume 127, Pages 133-149

http://dx.doi.org/10.1016/i.seares.2017.04.009

http://archimer.ifremer.fr/doc/00385/49660/

(c) 2017 Elsevier B.V. All rights reserved.

\title{
Variation that can be expected when using particle tracking models in connectivity studies
}

\author{
Hufnagl Marc ${ }^{1,{ }^{*}}$, Payne Mark ${ }^{2}$, Lacroix Geneviève ${ }^{3}$, Bolle Loes J. ${ }^{4}$, Daewel Ute ${ }^{5,15}$, \\ Dickey-Collas Mark $^{4,6}$, Gerkema Theo ${ }^{7}$, Huret Martin ${ }^{8}$, Janssen Frank ${ }^{9}$, Kreus Markus ${ }^{1}$, \\ Pätsch Johannes ${ }^{10}$, Pohlmann Thomas ${ }^{10}$, Ruardij Piet ${ }^{7}$, Schrum Corinna ${ }^{3,10,}{ }^{11}$, Skogen Morten ${ }^{12}$, \\ Tiessen Meinard C.H. ${ }^{7}$, Petitgas Pierre ${ }^{8,13}$, Van Beek Jan K.L. ${ }^{14}$, Van Der Veer Henk W. ${ }^{7}$, \\ Callies Ulrich ${ }^{15}$
}

${ }^{1}$ Institute for Hydrobiology and Fisheries Science, Center for Earth System Research and Sustainability (CEN), University of Hamburg, Olbersweg 24, D-22767 Hamburg, Germany

${ }^{2}$ DTU-Aqua, Technical University of Denmark, Charlottenlund Slot, Jægersborg Allé 1, 2920

Charlottenlund, Denmark

${ }^{3}$ Royal Belgian Institute of Natural Sciences (RBINS), Operational Directorate Natural Environment (formerly MUMM), Gulledelle 100, B-1200 Brussels, Belgium

${ }^{4}$ Wageningen Marine Research (formerly IMARES), Institute for Marine Resources \& Ecosystem

Studies, PO Box 68, 1970 AB IJmuiden, The Netherlands

${ }^{5}$ Nansen Environmental and Remote Sensing Center, Hjort Centre for Marine Ecosystem Dynamics,

Thormøhlensgate 47, 5006 Bergen, Norway

${ }^{6}$ International Council for the Exploration of the Sea, H. C. Andersens Boulevard 44-46, DK-1553

Copenhagen V, Denmark

${ }^{7}$ Royal Netherlands Institute for Sea Research, Department of Coastal Systems, Utrecht University, PO

Box 59, 1790 AB Den Burg Texel, The Netherlands

${ }^{8}$ IFREMER, Centre de Brest, RBE, STH/LBH, BP 70, 29280 Plouzané, France

${ }^{9}$ Bundesamt für Seeschifffahrt und Hydrographie (BSH), Bernhard-Nocht-Straße 78, 20359 Hamburg,

Germany

${ }^{10}$ Institute of Oceanography, Hamburg University, Bundesstr. 53, 20146 Hamburg, Germany

${ }^{11}$ Geophysical Institute, University of Bergen, Allégaten 70, 5007 Bergen, Norway

12 Institute of Marine Research, Pb 1870 Nordnes, N-5817 Bergen, Norway

${ }^{13}$ IFREMER, RBE/EMH, Rue de l'île d'Yeu, BP 21105, 44311 Nantes Cedex 03, France

${ }^{14}$ Deltares, PO Box177, $2600 \mathrm{MH}$ Delft, The Netherlands

${ }^{15}$ Helmholtz-Zentrum Geesthacht, Institute of Coastal Research, Max-Planck-Str. 1, 21502 Geesthacht, Germany

* Corresponding author : Marc Hufnagl, email address : marc.hufnagl@uni-hamburg.de

\begin{abstract}
:
Hydrodynamic Ocean Circulation Models and Lagrangian particle tracking models are valuable tools e.g. in coastal ecology to identify the connectivity between offshore spawning and coastal nursery areas of commercially important fish, for risk assessment and more for defining or evaluating marine protected areas. Most studies are based on only one model and do not provide levels of uncertainty. Here this uncertainty was addressed by applying a suite of 11 North Sea models to test what variability can be
\end{abstract}


expected concerning connectivity. Different notional test cases were calculated related to three important and well-studied North Sea fish species: herring (Clupea harengus), and the flatfishes sole (Solea solea) and plaice (Pleuronectes platessa). For sole and plaice we determined which fraction of particles released in the respective spawning areas would reach a coastal marine protected area. For herring we determined the fraction located in a wind park after a predefined time span. As temperature is more and more a focus especially in biological and global change studies, furthermore inter-model variability in temperatures experienced by the virtual particles was determined. The main focus was on the transport variability originating from the physical models and thus biological behavior was not included. Depending on the scenario, median experienced temperatures differed by $3{ }^{\circ} \mathrm{C}$ between years. This range between the different models in one year was comparable to the temperature range observed between all modelled years. Connectivity between flatfish spawning areas and the coastal protected area was highly dependent on the release location and spawning time. No particles released in the English Channel in the sole scenario reached the protected area while up to $20 \%$ of the particles released in the plaice scenario did. Interannual trends in transport directions and connectivity rates were comparable between models but absolute values displayed high variations. Most models showed systematic biases during all years in comparison to the ensemble median, indicating that in general interannual variation was represented but absolute values varied. In conclusion: variability between models is generally high and management decisions or scientific analysis using absolute values from only one single model might be biased and results or conclusions drawn from such studies need to be treated with caution. We further concluded that more true validation data for particle modelling are required.

\section{Highlights}

- A suite of ocean circulation and Lagrangian models were compared to determine inter-model uncertainty and variation. Absolute results (final positions, temperatures, fraction of particles reaching certain areas) varied between models, but trends between years were comparable. More plaice larvae than sole larvae reached a marine protected area although released in the same area but in different times of the year. About $10 \%$ of all herring larvae released in the southern North Sea were located in a wind-park area when becoming juvenile

Keywords : Ocean circulation, Lagrangian approach, Variability, Marine protected areas, Renewable energy, Wind park, Model intercomparison, Ensemble 


\section{INTRODUCTION}

Major questions in marine biology and habitat conservation have always been: where do species come from, where do they go to, how are marine habitats, nurseries and spawning areas connected, how do environmental factors influence marine animals and what kind of environment do different species experience (e.g. Caley, 1996; Christensen et al., 2008; Siegel et al., 2008; Jakobsen et al., 2009). In oceanography, marine chemistry and risk assessment, the tracing of water masses, chemicals, pollutants, lost cargo or castaways has motivated the development and improvement of ocean circulation models (OCMs) (Hackett et al., 2006). Indeed, these models are vital to understand complex environments where observations are scarce, available samples are patchily distributed, sampling is too expensive or other tools and methods are simply not existent. Thus OCMs and especially Lagrangian particle tracking modules linked to the OCMs have become more and more used in marine and larval biology since the earliest model drift studies performed e.g. by Bartsch et al. (1989) or later Heath et al. (1997) and van der Veer et al. (1998). Where larvae in these early approaches have been treated generally as "passive" particles different shades of complexity have since then been included and now mimic behavior like selective tidal transport or stage related vertical distribution pattern (Fox et al. 2006, van der Molenet al. 2007; Bolle et al., 2009; Savina et al., 2010; Lacroix et al., 2013), physiology (Daewel et al., 2008; Kühn et al., 2008; Fiksen and Jørgensen, 2011; Daewel et al., 2011a,b) or mortality (see review by Peck \& Hufnagl, 2012). With respect to the connectivity criterion of marine protected areas, OCMs and Lagrangian models have recently been used to also advice spatial planning and management in different regions (Delpeche-Ellmann and Soomere, 2013; Munroe et al., 2014; Engie and Klinger, 2007; Koeck et al., 2015). Coastal and shallow areas, are often used by several species as juvenile nursery area while eggs are generally spawned further offshore or in different locations. There is a general interest in understanding how many eggs or larvae are able to reach these coastal nurseries, which would provide valuable information to understand recruitment variability and ecosystem functioning.

Due to overfishing of certain stocks and the increasing anthropogenic influence on the ecosystem, several conservation zones, national parks and protected areas have been established in the past (Habitats Directive, 92/43/EEC from 21 May 1991). The largest one in the North Sea is related to fishing activities: the so called "plaice box" (Fig. 1). 
This area was established in 1989 (Pastoors et al., 2000) and closed to larger fishing vessels. The main aim of the "plaice box" was to protect flatfish nurseries and juvenile areas, although the benefits have been discussed controversially in the past (see Beare et al., 2010 and references therein).

Recently, the increasing number of areas designated to offshore wind energy generation has challenged marine spatial planners (Douvere and Ehler, 2009; Berkenhagen et al., 2010; Jacques et al., 2011) and the influence of introducing new concrete habitats and closing the designated areas to fishing activity is currently examined concerning the ecological and economic consequences (Boehlert and Gill, 2010; Lindeboom et al., 2011). Fish might get attracted by those areas or remain in their close proximity as soon as they pass them. Thus they would be protected as no fishing is allowed inside these areas. Additionally benthic invertebrates might settle on the hard substrates as soon as they reach the concrete structures. The amount of spat, eggs and larvae transported to and from these wind farms can so far best be analyzed taking the currents around these structures into account.

For the North Sea several OCMs which are suitable for such studies exist (a collection of those used in this study and the respective literature is summarized in Table 1). Some of these models have been developed independently, while some are related and were built upon originally similar equations, parameterizations and grid structures. However, the latter have with time diverged, as the focus of research changed and the models were used to investigate different questions. Thus diversity among models is high, as is the system they are used in and the questions they address. Each of the models performs reasonably well, covers the important dynamics on a seasonal, interannual and regional scale, as shown by the validation procedures presented in the respective model literature (see Table 1 and supplementary). From an oceanographic point of view, field temperatures, salinity data, heat fluxes at the air water boundary and water fluxes through certain areas (e.g. from current measurements Lane et al., 1999) have been used to validate OCMs (see references in Table 1). Comparing modelled drift routes with observations is generally more difficult than comparing the OCM derived fluxes or temperatures as specific field measurement are lacking against which results can be compared. Sub surface Argo floats mainly represent the combined effect of wind and surface currents and also show high variability in observed trajectories (Hill et al., 2008; Tiessen et al., 2014). In model drift studies generally 
several thousand particles are released while in reality experiments are restricted to much smaller numbers, although the observed diversity of routes taken by the buoys indicates that many more floats would be needed for a representative analysis. The case becomes even more complicated when "biological particles" like chlorophyll, plankton or fish are considered as they are influenced by an amalgam of behaviour, predator-, prey- and physical environment related factors (e.g. review by Peck and Hufnagl, 2012). Despite the uncertainties and difficulties in comparing field with model data the modelled distributions of any kind - estimated with those North Sea models used here - often provided reasonable results in comparison to field observations. This has been demonstrated e.g. between otoliths and model based growth and transport (Allain et al., 2003), timing of abundance maxima of fish larvae (Bolle et al., 2009) and year-to-year variability (Lacroix et al., 2016), modelled and observed distribution of plaice larvae (Hufnagl et al., 2013) or drift of buoys (Tiessen et al., 2014).

Where observation data are scarce further information on model performance can be gained from cross-comparisons with other models. Inter-model comparisons for different North Sea hydrodynamic models have been conducted in the past. Using a 2D approach Callies et al. (2011) compared four different OCMs in the German Bight indicating a substantial variability in drift routes between the different models, but also underlining the need for ensemble runs to address and identify causes and processes leading to these differences. Within the NOMADS and NOMADS 2 project nine different OCMs were compared (Delhez et al., 2004). Within the NOMADS studies, it was tried to achieve a higher comparability between models by applying similar forcing data, similar boundary conditions, similar heat flux formulations, similar river inflows etc. This approach could be challenged as each model is used, validated and programmed in a way that it performs best with the used input data and settings. Any change in the normally used conditions might lead to unforeseen model instabilities or changes in previously observed patterns. Within the NOMADS projects trajectories from a number of release studies, flows through predefined sections as well as mean salinities and temperatures were calculated, compared and analyzed (Delhez et al., 2004). Although the response of the different models to changes in forcing conditions (like reduced heat flux, increased bottom drag etc.) were comparable, the results showed a high degree of inter-model variability, which could not be further assigned to single factors or parameterizations. The extent of variability that resulted from the modification of the original settings was not determined. 
The unaddressed uncertainty and the observed deviation of the results obtained from different models raises the concern about the reliability of the advice that can be given based on these models. So far North Sea hydrodynamic model comparison studies were designed to identify differences between models and to learn about the influence of different parameterizations on the hydrodynamic properties. For example in the NOMADS study, other than the standard model-specific boundary conditions and forcing data sets were applied. The obtained results thus do not tell us anything about the variability that can be expected when the OCMs are used with their standard (best practice) settings. No confidence limits or uncertainty ranges can be provided when applying those models for advising spatial planning or examining connectivity patterns. To address this issue we designed a set of simplified notional scenarios where we started virtual fish larvae in their known spawning areas and calculated the fraction of juveniles that might settle in a marine protected area (plaice and sole and the plaice box) or that might reach areas designated for wind energy use (herring).

The main aim of this study was to enumerate the order of magnitude of variability resulting from choosing different physical models. To not complicate and overload the study we neglected biological behavior of the drifters. The authors are aware that this is an oversimplification of reality and not state of the art in biological drift studies. Conclusions drawn from this study which are related to the biology of the three test species are thus limited. Nevertheless, we considered it to be more valuable and informative for the reader relating the test scenarios to "real" test cases than simply running different scenarios without any biological background.

The clupeid Herring (Clupea harengus), North Sea plaice (Pleuronectes platessa) and sole (Solea solea) were chosen as model species in our analysis due to their commercial importance, their complex habitat structuring and the wealth of field and laboratory data. Plaice and sole require coastal areas as nurseries located within the plaice box (Zijlstra, 1972; van der Veer, 1986; Beverton, 1995; lles and Beverton, 2000). Juvenile and adult herring can form large schools, which are patchy distributed across the North Sea. Juveniles (age 0 to 1 ) generally show a higher abundance in the South (ICES HAWG, 2015) and might thus remain in wind park areas as soon as their swimming capacity is high enough to overcome the water currents. There they might find better feeding conditions due to increased productivity inside the park (Leonhard and Pedersen, 2006). 
As stated before, the aim of this study was to investigate the variability of the results obtained from a suite of North Sea drift models with regard to habitat connectivity, drifter locations and dispersal of drifters. We applied the different models to simulate passive transport (no behavior) of drifters started in plaice and sole spawning locations and their chance to reach a marine protected area located around the coastal nurseries of these two species. Furthermore, we tested which fraction of drifters released in two herring spawning areas (Banks or Downs) would be located in an offshore wind park at a time where juvenile herring start schooling. 


\section{MATERIALS \& METHODS}

In this study, we compared 11 different North Sea ocean circulation models (OCMs). Eight models resolved, besides longitude and latitude, also depth (3D, Table 1: lines $1,4-10,12)$ while four models integrated the vertical structure to one depth layer (2D, Table 1: lines 2, 3, 11, 13). One of the latter models was a "true" 2D model (Table 1: line 3$)$ while the other three $(2,1,13)$ were based on a 3D hydrodynamic model where lateral exchange was averaged vertically to generate a $2 \mathrm{D}$ input forcing field for the attached Lagrangian tracer module (Table 1: 2, 11, 13). One model: HAMSOM (Table $1: 8,10-12$ ), was used in four different versions defined by different spatial resolutions and model settings.

Eight different Lagrangian drift modules (LDMs) were applied. These were forced with the velocity data obtained from the OCM and time steps ranging from one day (Table $1: 8,10,12$ ) to less than 2 min (Table $1: 1$ ) or less.

\subsection{Models}

The OCMs covered the whole or at least parts of the North Sea (Fig. 2). In some cases also parts of the North Atlantic and/or the Baltic Sea were included besides the North Sea. General configurations, settings, resolutions and boundary forcing/settings are listed in Table 1. Additional information describing the models is provided as supplementary material. All used OCMs calculate water currents and flows based on a fixed grid structure. The format of this structure varies and can either consist of a spherical grid oriented along latitudes and longitudes (e.g. Table 1: 1-2, 5-13), a tilted grid with its center in the focus area (Table 1: 4), an unstructured grid (Table 1: 3) or gridlines that follow topographical structures (Table 1: 1, 4). Lagrangian movement of particles was determined in discrete time steps and positions were updated using the velocities determined by the OCM for the neighboring or closest grid nodes. Different approaches were followed in the LDMs to calculate and follow the positions of passive particles released along the preset start transects (see Fig. 1, descriptions given in the next section). Due to historical developments, each hydrodynamic model generally has a LDM counterpart, which has especially been developed and validated for that specific hydrodynamic model. The PELETS tracer model (Callies et al., 2011) forms an exception as it uses 2D (e.g. vertically averaged) OCM outputs of various different 
models (BSHcmod, HAMSOM, TRIM, TELEMAC). For the HAMSOM (in two different resolutions) and the ECOHAM OCM the same LDM was used, which allows for comparison of the transport solely depending on the OCM settings. For all remaining models (DELFT3d, ECOSMO, GETM, LARVAE\&CO, MARS3D, NORWECOM) individually different LDMs were used. More detailed descriptions of the OCMs and is provided in the supplementary material.

\subsection{Drift simulations, settings}

To make the test scenarios more realistic, the start locations, start times and drift durations were chosen to match important spawning locations and times of sole, plaice and herring. Sole spawn in coastal shallow areas in the southern North Sea during late spring (Lacroix et al., 2016 and ref. therein). Plaice spawn between late December and April in the southern North Sea (literature summarized in Bolle et al., 2009 or Hufnagl et al., 2013).

Herring is a demersal batch spawner (Geffen, 2009), in contrast to plaice and sole which are pelagic spawners. The North Sea herring population contains several subcomponents, which spawn in distinct areas along the UK coast (Schmidt et al., 2009) and later mix in the North Sea. The spawning season of the autumn and winter spawner components starts in August around the Orkney and Shetland Islands and ends in late December early January for the Downs component in the English Channel. Each simulated drift scenarios consisted of a combination of start time, start location and drift duration chosen according to the species-specific life cycles characteristics as outlined below.

All results were based on passive drift only meaning that no behavior of the particles was included.

\subsubsection{Start transects}

Scenarios were spatially restricted to the southern North Sea to obtain the area covered best by all OCMs (Fig. 2). Model fish eggs and larvae (from now on called particles) were released on seven different predefined transects (Fig. 1, Table 3). On each transect 50000 particles were released randomly at the start of each scenario run over all depth strata along the scenario transect. Sensitivity studies (shifting the start transect and the start times) and sub sampling of end positions (both not 
presented here) showed that all metrics that were analyzed here could be determined with high accuracy using 50000 particles.

Spawning areas of sole were represented by transects T1, T2, T3, T4 and T7, those of herring by transects $\mathrm{T} 1, \mathrm{~T} 2$, and $\mathrm{T} 6$ and those of plaice by all transects, respectively. To avoid problems concerning different bathymetry settings in the different models, all transects always ended at the first land point of each hydrodynamic model and not at a fixed latitude or longitude (Fig. 1, Table 2).

\subsubsection{Start dates and drift duration}

Start dates, drift durations, transect definitions etc. are described in Table 3.Total drift duration was set constant in all scenarios to solely focus on current and drift variability and was related to the larval development rates at average temperatures experienced during the early life stage following Bolle et al. (2009) for plaice (90 days) and Lacroix et al. (2016) for sole (60 days). Plaice spawning times are slightly different in the North Sea and thus plaice particles were started on day 1 in the English Channel (T1, T2), on day 45 on T3 and T4 and on day 73 in the southern North Sea (T5-T7). Scenarios representing herring ended in February where autumn spawned juveniles had reached a size of approximately 30-35 mm (Hufnagl et al., 2014) enabling them to swim with speeds of $0.1 \mathrm{~m} \cdot \mathrm{s}^{-1}$ (Munk and Kiørboe, 1985), which is in the order of current speeds observed in the North Sea (Bartsch, 1993) and where they start schooling $(35-40 \mathrm{~mm}$, Gallego and Heath, 1994). February is also the time where juvenile herring are sampled by the surrounding North Sea states in an international survey (IBTS MIK survey). Downs herring spawning in the English Channel display a spawning peak in early January and therefore calendar day 1 was chosen as start day. Banks herring, here represented by Transect 6, spawn in autumn and were therefore started on calendar day 257 of the previous simulation year.

\subsubsection{Start years}

Simulation years were chosen based upon observed average temperatures and NAOindices (Hurrel, 1995 and supplementary material). The NAO is well correlated to hydrodynamic conditions in the North Sea. Years with a positive index are characterized by increased water circulation (Siegsmund and Schrum, 2001), higher 
wind speeds and warmer temperatures (Hurrel, 1995). Years with a negative NAO are generally colder and less windy. Differences in circulation patterns and temperatures were expected to occur between years with strongly differing NAO. Four different years (1996, 1998, 2002, 2005) were used in the simulations representing the highest possible variability concerning the NAO index and water temperature anomalies within the period restricted by the availability of the OCM outputs and setups (generally 1990 2006). The year 1996 represented a cold $\left(0.5^{\circ} \mathrm{C}\right.$ colder than the long-term average) year with negative NAO index $(-0.1), 1998$ a warm $\left(+1^{\circ} \mathrm{C}\right)$ neutral NAO index $(0.05)$, 2002 and 2005 warm $\left(+1.5,+1.3^{\circ} \mathrm{C}\right)$ and positive $(0.4)$ or negative $(-0.1)$ NAO index, respectively. NAO index and temperature anomalies were obtained from www.cpc.ncep.noaa.gov.

Following the previously described settings, in total 60 scenarios were calculated (15 scenarios per year $\mathrm{x} 4$ years).

\subsubsection{Missing data sets}

Not all models were available for all years and all areas. BSHcmod hydrodynamic model forcing for the LDM was not available for years before 2000 and therefore BSHcmod-PELETS could not be used for the 1996 and 1998 scenarios. DELFT3D model runs were not available for 1995 and therefore the herring run that started in 1995 and ended in 1996 could not be calculated, similarly to the MARS3D model runs. The domain of the HAMSOM $3 \mathrm{~km}$ version ended at $51^{\circ} \mathrm{N}$ and therefore scenarios using T1 and T2 could not be calculated. With the LARVAE\&CO and the GETM models, HeT6 scenarios were not calculated as with the current LDM set up starting a model run in a year different from the end year was not available. Also for the specific version of GETM no SoT7 runs were available. TELEMAC forcing data ended in 2002 and therefore 2005 scenarios were not included. Additionally, transects T1 and T2 were not calculated with TELEMAC-PELETS as forcing data for the area south of $51^{\circ}$ north were not available, in addition no temperatures were provided for this model.

\subsection{Model output and comparisons}

Scenarios were chosen to match comparable approaches one might use in a spatial management and advice processes. Here pelagic drift duration and start points were 
based on spawning times and drift durations of the larval stages of commercially important species. We analyzed what fractions of the two flatfish species released in known spawning areas would reach a marine protected nursery area. Furthermore, we determined which fraction of herring juveniles that hatched in the Downs or Banks area would be located in planned wind park areas.

In addition, the ranges of determined positions at the ends of all drift scenarios and the mean temperatures experienced during the drift phases was analyzed. By combining the end positions obtained from all OCM-LDM combinations applied in one scenario ensemble maps were provided indicating the most likely or unlikely positions of particles at the end of each scenario.

In total 780 model $x$ scenario combinations were possible based on 4 years, 15 scenarios and 13 OCMs-LDMs. However, not all models covered all areas and years as described before. Only some selected example runs are provided in this manuscript. To visualize the behavior of the models in different areas of the North Sea and during different seasons, three scenarios were chosen: HeT6 (Banks herring autumn spawner starting in Sep. and drifting until Feb.), PIT2 (plaice Eastern English Channel, starting in Jan. and drifting until Apr. 1 ${ }^{\text {st}}$ ) and SoT7 (sole German Bight, starting in May and drifting until July). Where possible and feasible all results of all scenarios are shown. These three scenarios were chosen as they cover most areas, start times and drift durations.

\subsection{Ensemble based on all models}

Final particle positions obtained from all LDMs were combined to obtain ensemble distributions for the selected scenarios. Particle densities were determined by summing up all final positions obtained from the 13 OCMs-LDMs. An underlying regular grid of $0.1^{\circ} \times 0.1^{\circ}$ was applied. Results of each model were normalized by the total number of particles initialized $(13 \times 50000)$ minus the number of particles that left the model domain. The latter were not included in any of the analysis. For all 3D OCMsLDMs the particle positions were reduced to $2 \mathrm{D}$, neglecting depth, and all results were plotted by longitude and latitude only. 


\subsection{Particle distributions and boxplots per scenario, year and model}

Variability of end positions and temperature experienced by the particles were analyzed using boxplots. All boxplots shown in the manuscript indicate the 25, 50 (median) and 75 percentiles and were calculated based on the entity of all particle locations per model, year and scenario except those that left the model domain. In addition to the longitude and latitude boxplots the respective percentiles for the average temperature experienced by a particle in the respective scenario was calculated.

\subsection{Fraction of particles that reach the plaice box or wind park areas}

The plaice box covers the coastal areas along The Netherlands, Germany and Denmark (Fig. 1). Wind parks areas were located further offshore (Fig. 1). For scenarios representing plaice and sole the fraction of all released particles that reach the plaice box was determined. For herring scenarios, the fractions of particles ending in planned, authorized or fully commissioned wind park areas (www.4coffshore.com) were calculated.

\subsection{Model clustering}

Metrics were defined that characterize the particle distribution to be able to identify which models provide comparable results and to identify potential factors that determine the variability between models. These metrics referred to the entity of the end-positions of all particles per scenario and could be defined and described by different parameters, like for example the center of the kernel (mean latitude and mean longitude position) or the shape of it. These properties will be referred to here as kernel statistics or kernel parameters.

For each scenario - at the end of each simulation - the following set of variables was saved for each particle: [1] used model, [2] scenario, [3] start longitude, [4] start latitude, [5] end longitude, [6] end latitude. As stated earlier temperature becomes more and more important especially in climate related studies, therefore [7] mean water temperature experienced during drift was added. To get an indication on the 
general water depth and vertical dispersion of the particles also [8] mean water depth during the drift was added. The end positions were used to calculate kernel statistics following largely Huret et al. (2010). From this analysis we obtained 12 parameters: [1] mean longitude, [2] mean latitude, [3] major axis length of the kernel (longest extension of the ellipse of end positions), [4] minor axis length of the kernel (shortest extension of the ellipse), [5] theta: the tilt angle of the kernels' major axis, [6] distance between mean start and mean end position, [7] angle between mean start and mean end position, [8] positive area, [9]. equivalent area, [10] coefficient of variation in density, [11] mean (over all particles) of mean temperature experienced along the drift route and [12] mean (all particles) of mean (over drift route) experienced depth.

Based on the kernel parameters a cluster analysis was processed analyzing the model effect. The clusters were calculated using inner squared distance (minimum variance algorithm) based on the Euclidean distances. The results are dendrograms that showed the grade of similarity between the used models. 


\section{RESULTS}

\subsection{Ensemble distributions}

Differences in the extent of dispersal and retention between years and between scenarios were determined (Figure 3). For a given scenario, the mean end location (center of mass indicated by the red dot and calculated based on all particles from all models in Figure 3) displayed significant variability between different years.

Particles representing plaice and starting in January in the eastern English Channel (the SW entrance to the North Sea: scenario PIT2) were transported within the 90 days enduring drift time mainly towards the east. In April the majority of particles (centers of masses) were located in the northern part of the Southern Bight (the prolongation of the English Channel) at approximately $53^{\circ} \mathrm{N}$ in the years 1996, 1998 and 2002. For these three years the ensemble distribution patterns were comparable. In contrast to these patterns the center of mass was located close to the release transect in 2005 and a larger fraction was transported towards the west into the English Channel. In 1996 and 2005 the majority of particles was transported towards the central North Sea. In 1998 and 2002 more particles were located close to the shore at the end of the drift period (Figure 3).

Herring scenario HeT6 included particles released on transect 6 (western North Sea, UK coast) in September and transported passively for 146 days. This scenario roughly represented spawning areas and times of Banks herring. Strong interannual differences were observed. In February 1996 - at the end of the drift period - most of the particles were located close to the release area in the western North Sea. In 1998 and 2002 the majority of the particles were transported towards the eastern North Sea, the Danish coast and the Skagerrak (eastern connection between the North and Baltic Sea) and the center of mass was located at about $4^{\circ} \mathrm{E}$. In 2005 particles were dispersed strongest and were spread over the German Bight and along the southern Norwegian coast (Figure 3).

Sole larvae were modeled in scenarios using transects T1, T2, T3, T4 and T7. For transect T7 (scenario S0T7), particles started in May and ended in July. In all years sole particles were retained close to the release transect in the German Bight, but dispersed strongest in the year 2002 (Figure 3). In contrast to HeT6 the particles in SoT7 were retained most in the year 2005. 


\subsection{End positions per scenario, year and model}

Mean end positions obtained from the different models for the PIT2, HeT6 and SoT7 scenarios and the four different years were in general agreement but a significant intermodel variability existed (Figure 4). Particles released in scenario PIT2 were transported into the North Sea in the years 1996, 1998 and 2002 in all models except MARS3D. Particles were transported the furthest northeast applying the TRIMPELETS, the NORWECOM and the LARVAE\&CO model. Within the PIT2-2005 (Figure 4d) scenario the deviation of the obtained mean end-points was highest between all models. In the MARS3D, LARVAE\&CO and BSHcmod-PELETS model scenarios particles were transported westwards into the English Channel, in the HAMSOM-PELETS, DELFT3D and ECOSMO runs particles remained close to the release position and in the remaining model scenarios particles were transported into the Southern Bight.

Particles released in the HeT6 scenario were always - with all models - transported to the east (Fig. 5). In comparison to 1998, 2002 and 2005 the transport distance was lower in 1996 as described earlier for the ensemble result (Fig. 3). In all years, except 1996 (Fig. 5a), particles from the TELEMAC-PELETS (purple, Fig. 5 b-d), MARS3D (blue, Fig. 5 b-d) and HAMSOM3 (cyan, Figure 5 b-d) models were transported east or southeast whereas in the remaining models particles were transported to the northeast.

Particles released in the German Bight in scenario SoT7 (Fig. 6) were not transported as far as in the PIT2 (Fig. 4) or HeT6 (Fig. 5) scenarios and remained close to the release location. Due to the generally lower transport distances in this scenario the inter-model variability was also lower. Highest transport rates were calculated with the ECOSMO model in 1996, 1998 and 2005 (light green, Fig 6abd), lowest with the TELEMAC- (purple Fig. 6) and TRIM-PELETS (red, Fig. 6) model.

\subsection{Boxplots of longitude, latitude and mean temperature}

Boxplots of all end positions separated by longitude and latitude, and of all averaged temperatures are shown in Fig. 7. Deviations of each model from the observed median of all models are provided in Fig. 8. While the first figure allowed for a comparison of 
the year-to-year and scenario variability the second helps to identify e.g. whether one model always provided higher or lower temperatures or whether currents were always stronger in one model than in the others. Fig. 7 only included the three focus scenarios PIT2, HeT6 and SoT7 whereas Fig. 8 includeed all scenarios.

In scenario PIT2 particles were transported about 1.5 to $3^{\circ}$ eastwards and 1 to $6^{\circ}$ northwards (Figure 7). The median longitude (red horizontal line) was $1.8^{\circ} \mathrm{E}$ and the median latitude $51^{\circ} \mathrm{N}$ and about $4^{\circ} \mathrm{E}$ and $53^{\circ} \mathrm{N}$ in 2005 and 2002, respectively. Average temperatures experienced by particles during their entire drift displayed interannual differences. Lowest temperatures were experienced by particles in 1996 with $5.2^{\circ} \mathrm{C}$ in contrast to 1998 with $7.8^{\circ} \mathrm{C}$.

Comparable to PIT2, highest displacements in the HeT6 scenario were observed in 2002. The remaining years did not show strong differences with the exception of the longitudinal end-positions in the $1996-\mathrm{HeT} 6$ scenario, which were at about $2^{\circ} \mathrm{E}$ in comparison to $4.5^{\circ} \mathrm{E}$ in the corresponding 1998 and 2005 scenarios. Temperatures in the HeT6 scenarios varied between the models and lowest temperatures experienced particles in the ECOSMO and NORWECOM model, highest in the DELFT3D and HAMSOM models.

In the SoT7 scenario, independent of the year and the model, almost no displacement of particles was observed longitudinally. The median latitude was about $55^{\circ} \mathrm{N}$ in 1996 , 1998 and 2005 and $55.5^{\circ} \mathrm{N}$ in 2002. Lower temperatures were determined in 1996 $\left(11^{\circ} \mathrm{C}\right)$ and $2005\left(12^{\circ} \mathrm{C}\right)$ than in $1998\left(13.5^{\circ} \mathrm{C}\right)$ and $2002\left(14^{\circ} \mathrm{C}\right)$.

Particles experienced significant lower (Wilcoxon signed rank test, $p<0.01$ ) temperatures in the BSHcmod-PELETS model (Fig. 8) in comparison to the median temperatures provided by all models (for each year and scenario). Significant higher temperatures were obtained from all HAMSOM derived models $(\mathrm{ECH}, \mathrm{H} 2 \mathrm{O}, \mathrm{H} 03, \mathrm{HAP})$ and LARVAE\&CO. When comparing the deviations of the particle longitudes and latitudes from the median longitudes and latitudes a stronger displacement of particles to the south west, in the MARS3D model, and towards the north east, in the NORWECOM model, was observed (Figure 8). In nearly all cases the deviation obtained from one model for all years but one scenario were comparable, meaning if for example GETM results for HeT1 predicted a stronger transport towards the east in 1996 (compared to the median of all models used for HeT1 1996), then this was also the case for 1998, 2002 and 2005. 


\subsection{Cluster analysis}

Based upon the kernel parameters a cluster analysis was conducted. Three main groups of related models were identified (see Table 1). One was formed by TRIMPELETS and TELEMAC-PELETS together with NORWECOM, ECOSMO and LARVAE\&CO, the second by HAMSOM ( $3 \mathrm{~km}, 20 \mathrm{~km}$, PELETS), ECOHAM, BSHcmodPELETS, DELFT3D and GETM and the third by MARS3D, respectively. The OCMLDMs of the first group used similar spatial resolutions of $10 \mathrm{~km}$ and less and time steps of 1 hour or less. Most of the models of the second group were offline coupled to the OCMs and most used nested grid structures or grids where grid points were more than $10 \mathrm{~km}$ apart. The second group also used, with the exception of GETM, fixed horizontal diffusion parameters. The third group only contained the MARS3D model which has a different spatial domain than the remaining models but used a high spatio-temporal resolution.

\subsection{Connectivity to the plaice box and wind parks}

The fraction of particles released in the plaice and sole scenarios and ending up in the coastal protection area ("plaice box") varied for the different release locations (Fig. 9) between 0 and $100 \%$. Focusing on sole, first no particles (besides NOR) reached the plaice box if they were released on T1 or T2. If they were released on T3 and T4 the median fraction reaching the plaice box was $0 \%$ (1996 and 2005) 12-15\% (1998) and $20-25 \%$ (2002), respectively. For T7 median fractions of particles in the plaice box were $>75 \%$. Particles released in the plaice scenarios reached the plaice box also for T1 and T2 (except for 2005), although median fractions were low (0 to 20\%). From T6 no particles (except for MAR simulations) reached the plaice box indicating a generally low connectivity between the British and the continental coast for plaice larvae. For T7 connectivity was generally high ( $>75 \%$ ) comparable to the sole scenarios.

Herring released on T1, T2 or T6 always reached North Sea wind park areas (Fig. 10). In 2005 where the transport of water through the English Channel into the North Sea was lower in comparison to 1996, 1998 or 2002, the fraction of particles ending in wind parks was lower (median of all models $0 \%$ ). 
While median fractions determined with all models varied between the years even stronger inter-model variations were determined. While for SoT4 for example ECOSMO predicted $75 \%$ of all particles to be located in the plaice box it was only $5 \%$ for the MARS3D model (Fig. 9, left). Comparable differences were obtained for the other models and scenarios as well.

\section{DISCUSSION}

\subsection{General considerations}

A process often addressed when dealing with ocean circulation models and Lagrangian drift modules (OCMs-LDMs) is the transport of matter with ocean currents. The multitude of factors that influence the exchange and flow of water masses as well as the involvement of unresolved small-scale processes makes it difficult to give a measure of certainty or an error range. It is not always possible to compare model transport rates or current velocities at a single position with field measurements as spatio-temporal scales do not always match and time series are rather short (days to week) in relation to the time series generated by the models (years to decades). One way to determine uncertainty or to provide ranges of expected variability is the analysis of ensemble results and model comparisons as done in this study.

There is generally a trade off when considering all factors and features of a large and complex system like e.g. the North Sea. If models represent observations reasonably well on a large scale they might still fail on a small scale, which has been shown e.g. for global climate models that explain well global climate but might not be able to reproduce features on the regional scale (Giorgi and Franscisco, 2000; Murphy et al., 2004; Wang, 2005; van Ulden and Oldenborgh, 2006).

The evaluation of larger scale patterns potentially hides minor uncertainties that - when considering the whole system - might not be of large importance, but are of higher relevance when addressing smaller scale questions. In particular for Lagrangian drift studies the dependency on small scale features is of importance and since drift models use the output of OCMs as input already small uncertainties included each time step will sum up over time and will become relevant. Notably due to slightly different vertical 
displacements particles may enter very different drift regimes leading to strongly diverging particle trajectories (König and Schrum, 1997).

Intra-model variability can be addressed to a certain degree by running a model with different settings or by creating different scenarios as done for example by Hugget et al. (2003). In contrast to this, the aforementioned scale related uncertainty can only be addressed using high resolution field data to detect where the model deviates from the reality. If such data are not available one general attempt is the analysis of ensemble runs and intermodel comparisons as for example done in the context of the IPCC climate forecasts. Field data often address/resolve different scales and studies using inert particles/drifters are scarce. In this study we used model ensemble runs and model comparisons to identify and enumerate model uncertainty and to get first rough insights into the transport patterns of fish larvae. As no behavior was included these results can so far only provide the general direction of transport. However, earlier studies showed that when including behavior these routes can be altered significantly (Fox et al., 2006; Fiksen et al., 2007; Vikebø et al., 2007; Bolle et al., 2009). Neglecting behavior in the models makes the biological representativeness of the results arguable as especially vertical migration in stratified water bodies and tidally and seasonally changing current fields lead to differences in the drift trajectories (see for example de Graaf et al., 2004; Fox et al., 2006; Bolle et al., 2009; Savina et al., 2010).

One motivation for this study arose from modeling studies dealing with plaice. In those studies Bolle et al. (2009) and Hufnagl et al. (2013) found only low transport rates from a known spawning area (T5) to the coastal nurseries. This raised the question if this was 1) model dependent, 2) real or 3) if some basic behavior was missing in the models. A large fraction of the PIT5 transect crosses this plaice spawning area that is located south of Dogger Bank (Harding et al. 1978, Taylor et al., 2007). In all PIT5 scenarios and whatever model was used, only a low fraction of larvae that started in that area reached the coast (a median of about 10\% reaching the plaice box) where the nurseries of plaice are located (Zijlstra, 1972; van der Veer, 1986). This general finding of low transport success therefore indicates that the low connectivity between the spawning area and the nursery is not a model related result as all models predicted it. This suggests that the fraction of larvae reaching the nursery was real or that, and based upon the known specific behavior of plaice this is more realistic, some basic understanding in the plaice early life stage behavior e.g. tidally cued vertical migration 
(e.g. Fox et al., 2006), is missing. Conclusions drawn from the connectivity analysis presented here need to be interpreted very carefully, as it should be done for all drift studies that treat larvae of any kind (benthos, fish) as passive particle.

We observed high inter-model, inter-scenario and interannual variability. In some cases the variability resulting from using different models (e.g. in the same scenario and year) was higher than the variability determined between the years, so intermodel variability exceeded interannual variability. This high variability becomes of an issue if one is interested in the "real" (absolute) final particle position. It is less of an issue if interannual trends (time series, trends) shall be analyzed, e.g whether the fraction transported eastward is higher in one year than in the other. Here we tested four different years so stating conclusions related to a time series is only vaguely possible. When we compared the deviation of single models from the whole ensemble mean it became obvious that in general those models that showed lower transport rates or temperatures in one year, or a general transport of particles into one direction, also performed similar in other years and scenarios. For example particles were transported with the BSHcmod, NORWECOM or TRIM forcing deeper into the North Sea (all years) while those with MARS3D or TELEMAC showed lower transport rates. For particles released in the German Bight highest transport distances were obtained with the ECOSMO model.

Based on the findings it can thus be concluded that analyzing time series using only one model will lead to a systematic bias in absolute values but provide reasonable results on a relative scale, which should be considered in future studies.

In a regional model of the Barents Sea, the magnitude of the flow is determined by the large-scale sea level gradient between the different open boundaries (Harms et al., 2005), a quantity which depends on the properties of the larger scale models providing boundary conditions. The North Sea is mainly determined by the inflow through the northern boundary and the wind field, but the flow through the English Channel and the connection to the Skagerrak can be of local importance as well. In addition, volume fluxes between the North Sea and Baltic Sea occur, with the Baltic Sea buffering these volumes on time scales of weeks and even months (e.g. Janssen et al., 2001). These water volumes have a strong influence on the salinity in the Skagerrak and might occasionally change the circulation in the northeastern North Sea. Model performance might be sensitive to the way the open boundary to the Baltic Sea is treated. Moreover, 
the model setup, whether it is barotropic (neglecting baroclinic pressure gradients for the flow field), diagnostic baroclinic (using a frozen density field) or baroclinic prognostic (time dependent temperature and salinity, forced by realistic freshwater and heat fluxes) are important for a realistic flow field (e.g. Langenberg and Pohlmann, 1994).

Generally, the results are mixed and in all three clusters comparable parameters can be found. 2D and 3D models occur together in a cluster and models with comparable atmospheric forcing and boundary conditions occur in different clusters. The used spatial domains and the model focus regions partly explain the differences between the models. The two main groups determined during the clustering mainly differ in their spatial and temporal resolution and the way diffusion is included. This is not true for all models but generally the models with a grid resolution of $10 \mathrm{~km}$ from one group. Concerning the time step the pattern is less clear. TRIM-PELETS, TELEMACPELETS, NORWECOM, LARVAE \& CO and ECOSMO use a LDM time step of $1 \mathrm{~h}$ or less and they form one larger cluster of models. The other cluster contains HAMSOM with a $1 \mathrm{~h}$ (HAMSOM-PELETS) and $24 \mathrm{~h}$ time steps, GETM with $45 \mathrm{~min}$ and BSHcmodPELETS and DELFT3D with 15 min time steps. Also the ECOSMO, BSHcmod together with the TRIM models are the only models that also included the Baltic Sea. The latter was in all other models either treated as a big river or was simulated using a climatological forcing. Due to the close proximity of the German Bight to the Skagerrak (the connection between the North and Baltic Sea) this dynamic modelling of the water exchange will influence the transport rates. Although for SoT7 in 1996, 1998 and 2005 the particle positions predicted by ECOSMO were located the furthest north it could be that these transport rates are more realistic due to the dynamic link between North and Baltic Seas. Four of the seven transects studied here were located in the English Channel which often forms the south western, or, as in the case of the MARS3D model with transects located within the North Sea, the north eastern boundary of the model system. Thus, these scenarios were sensitive to the flow, which is set and determined by the boundary settings. Although unlikely but following the argumentation line before for the North and Baltic Seas it could again be that the transport distance by MARS3D, which is in some cases opposite to the other models, is more realistic as the flow outside the North Sea was calculated with a higher spatial resolution. 
Other issues, which significantly influence the models performance and contribute to inter-model variability and uncertainty are the parameterization of turbulence, the model resolution (both, horizontally and vertically), the atmospheric and riverine forcing data and the numbers and selections of tidal constituents (Proctor, 1997; Delhez et al., 2004). Moreover also numerical schemes implemented (e.g. the advection scheme) contribute significantly to the performance of the models (e.g. Barthel et al., 2012).

In most cases it is not known what the "real" conditions are since good validation data for the comparison of drift rates are rare and only sporadically available (Bartsch, 1993; Svendsen et al., 1990; Mittelstaed and Soetje, 1982). Single buoys have been released and followed in the field, which can be used as e.g. shown by König and Schrum (1997) or Tiessen et al. (2014), but only to a certain extent. Other potential tracers such as larvae, zooplankton and chlorophyll as well as nutrients like nitrogen undergo natural production/degradation processes and are therefore of limited value. More inert substances like Rhodamin can be applied as shown by Langenberg and Pohlmann (1994) and Schrum (similar field data but using ECOSMO, unpublished).

Generally buoys or drifters released in the field are either mainly influenced by the surface currents (and therefore the wind forcing and not the hydrodynamic model) or the number of buoys followed is simply too low to even cover the variability in the field and to obtain representative patterns. Real drifters released in close proximity in the field will therefore follow different routes (Dooley, 1974; Hill et al., 1993) due to small scale effects like eddies (Booth and Meldrum, 1987), fronts or turbulence which are often not fully resolved by the models. Drift modelers circumvent this issue by including random noise in their models (e.g. diffusive random displacement following Visser (1997) or random walks as proposed e.g. by Daewel et al. (2008) and by running a large number of particles, which then provides probabilities where the real location could have been.

\subsection{Model comparison}

For each scenario analyzed in this study we observed partly strong variations between the final positions or the fractions that ended in the plaice box or designated wind park areas. Additionally inter-model variability was comparable to the observed interannual variability. First of all the years chosen were restricted by the availability of the model outputs (1995-2005) and therefore interannual variability was not as high as it would be expected from a long-term time series. Although the selected years differed 
concerning NAO and temperature regimes, larger differences between years have been observed e.g. for the period 1970 to 2013 (http://www.cpc.ncep.noaa.gov). Second, the fact that each model covers the North Sea and aims at explaining the same processes (i.e. transport processes), does not mean that they all have been developed for the same purpose and/or use the same underlying assumptions. Additionally, the regional focus was different as e.g. MARS3D mainly focuses on the Bay of Biscay and the North Sea is mainly a boundary, DELFT3D focusses mainly on the Dutch coast, HAMSOM3 covers the North Sea north of $51^{\circ}$, BSHcmod and ECOSMO include the transition between North and Baltic Sea and the first is used for operational short term tide and current forecasts, NORWECOM focuses on the Norwegian coast and GETM has been developed based upon a general oceanographic model framework adjusted to the southern North Sea conditions comparable to LARVAE\&CO.

No statement can be given on which model is generally right or wrong but we can state how different models behave in comparison to others in a certain region. The high complexity, the different model setups, resolutions and forcing data make it also difficult to pinpoint which factors mainly contributed to the inter-model variability, which is in line with earlier studies that used larger resources and spent more effort on identifying the "why are models different" question (Delhez et al., 2004). However, three major factors that might play an important role are: 1) the model resolution, 2) the forcing data and 3) the boundary condition and the distance from the boundary.

Differences of up to 1.5 degree in mean particle end position originated from using 2D (vertically averaged or full 2D) or 3D approaches as illustrated by the HAMSOMPELETS and the HAMSOM20 outputs which were based on the same hydrodynamic 3D model but use different LDMs. These differences are smaller than the maximum differences in particle end position between the different models, but taking into account that the drift simulation results actually arose from the same hydrodynamic model simulation, these could be considered substantial. Changes in the vertical drift position can lead to considerably different particle trajectories (König and Schrum, 1997) and it is known from field observations and model results that current vectors in the southern North Sea show substantial vertical rotation (Backhaus, 1980; König et al., 1993; Schrum, 1997), resulting in different current directions in climatic average, even in well mixed winter conditions (Schrum und Siegismund, 2003) It was earlier 
shown that including vertical migration behavior in drift models resulted in similar differences in particle position and drift trajectories in other regions (Fox et al., 2006; Fiksen et al., 2007; Vikebø et al., 2007; Bolle et al., 2009; Savina et al., 2010).

Another factor contributing to inter-model variability is the atmospheric forcing (Proctor 1997) and those with similar forcing grouped together. Even small differences within this factor might have played a role as e.g. connectivity patterns were comparable for the NCAR/NCEP driven models (ECOSMO, ECOHAM and HAMSOM) although they were different for the TRIM model that used CoastDat forcing nested into NCAR/NCEP. This might be due to the close relation of the ECOSMO, ECOHAM and HAMSOM models since all three models have a similar "root" model described by Backhaus (1985). Based on this model the ECOSMO (Schrum and Backhaus, 1999) and the HAMSOM3 (Pohlmann 1996, 2006) models were developed. Their main difference e.g. sea ice, light transmission and advection scheme (Barthel et al., 2012) are described in the supplementary material.

MARS3D forms a separate cluster in the cluster analysis. One reason could be the proximity of the study area to the boundary but a final conclusion cannot be drawn from the present analysis.

\subsection{Consequences for ecological modelling studies}

Although growth, mortality or behavior was not explicitly considered here, the results provide insights into general drift patterns and hydrodynamic impacts on early life stages of different fish species. Additionally, the study indicates areas where none of the passively drifting particles ended, which represents areas of generally lower connectivity to spawning areas. For example, the eastern North Sea (T7) was not connected to the UK coast and particles were generally retained in the German Bight, whereas particles released in the western part of the North Sea (T6) were able to potentially reach all North Sea areas shallower than $50 \mathrm{~m}$. Already based on these dispersion patterns it can be assumed that species using these different habitats follow different life history strategies. Herring nurseries are located in shallow areas of the southern North Sea (Corten, 2013) and thus in far distance from the spawning areas. Herring would thus benefit from high dispersal. Sole nurseries (shallow coastal areas) and spawning areas largely overlap and sole would thus benefit from retention. Additionally, particle released in the Southern Bight and the Eastern English Channel mainly ended on the Belgian and Dutch coast (e.g. with plaice recruitment) whereas 
particles form the German Bight only drifted towards the northern German and Danish coast. These findings are in line with tagging studies and previous findings about the general circulation of the North Sea (e.g., Hainbucher et al., 1987) or model studies on sandeel in the same area (Christensen et al., 2008). The plaice scenarios further indicate that the fraction of larvae that reach the Baltic Sea or the Skagerrak is limited which is in line with recent management plans that propose to separate the North Sea and the Skagerrak population due to spatial separation (Ulrich et al., 2013).

Although scenarios PIT1/T2 used the same transects as SoT1/T2, connectivity with the plaice box differed for the two species. The shorter development times of sole which spawn in late spring and early summer, led to a case where the majority of particles reached the southern UK coast in contrast to "plaice" particles that mainly reached the continental coast. This indicates that not only the spawning area but to a large extent also the spawning time (see also Edwards et al., 2007; Huret et al., 2010) and correspondingly longer drift duration (Shanks, 2009; Daewel et al., 2011b) influence connectivity. While connectivity of plaice spawning areas to the plaice box was observed in all scenarios beside T6, the connectivity in sole scenarios was not given for $\mathrm{T} 1$ and $\mathrm{T} 2$ indicating that spatial management based on defining conservation areas needs to be species specific.

Herring larval survival is not determined by the fraction of juveniles that reach a suitable nursery, as it is the case for sole and plaice, but is more related to the winter conditions (Payne et al., 2009; Alvarez-Fernandez et al., 2015). Conserving special nursery areas is therefore not a practicable management option to increase stock size. Nevertheless, if wind park areas would represent islands of higher productivity as e.g. assumed by Linley et al., (2007) the rate of transport into these areas might potentially influence survival either positively through increased prey availability or negatively through increased predation. The distribution pattern created here and based upon the ensemble approach indicated that herring originating from Downs (T1, T2) will, if no behavior is assumed and only passive drift is considered, mainly be transported across Dutch and German wind parks and might seldom be found North of $51^{\circ}$. This is in line with management and survey assumptions where larvae and juveniles caught in the Southern Bight are treated as Downs larvae (ICES HAWG, 2016) although within single years there could a substantial fraction also be transported into the Skagerrak area as observed in 2016. According to the transects chosen here and in line with 
studies that examined particles released in the whole spawning area (Hufnagl et al., 2015) only a low fraction of Banks herring larvae (T6) will reach areas south of $51^{\circ}$; however, these larvae have the potential to become distributed over the whole southern North Sea. Of all larvae released in the Downs and the Banks area in our simulations about 1 out of 20 to 1 out of 10 particles representing herring were located within a wind park area in February.

\section{CONCLUSION}

Several North Sea drift models have been compared to address variability and resulting uncertainty, and differences between the different models have been observed that were often higher than the interannual differences of the median of all models. LDMs become more and more used in the definition and evaluation of marine protected areas where they are used to determine larval exchange or to enumerate the risk of the MPA to be exposed to toxic substance (oil, litter, produced water) released in remote places. So far studies that validate LDMs and connectivity simulations are scarce but due to their nature LDMs integrate errors of the OCMs in each time step and high variability can be expected as also shown in this study with the difference that it is now possible to identify the level of uncertainty. The results suggest that individual models might deviate from the ensemble mean but that generally this bias is systematic and not random. Using model results to analyze e.g. trends in time series or to make predictions whether connectivity increases or decreases might thus be valid while fully relying on absolute outputs might significantly bias the drawn conclusions. In climate simulations (e.g. www.IPCC.ch) ensemble runs are assumed to be closer to the reality than single models, but as we have no validation test case for our simulation this assumption cannot be underlined or rejected here. However, the analysis done here relating each model to the median behavior of other models helps illustrate the range and deviation of single models in individual areas. Grading models according to their accuracy was not possible. However, the observed variability between the models shows the urge for more field data that can be applied for this purpose. 


\section{ACKNOWLEDGEMENTS}

Funding for the study was provided by the projects "ECODRIVE" (ECOsystem Change in the North Sea: Processes, Drivers, Future Scenarios, EU MarinERA); "RECLAIM" (REsolving CLimAte Impacts on Fish Stocks, EU FP6, 044133); "VECTORS" (Vectors of Change in Oceans and Seas Marine Life, EU FP7, 266445). European Commission's 7th Framework Programmes 'Marine Ecosystem Evolution in a Changing Environment', (MEECE, No. 212085); 'EU Basin-scale Analysis, Synthesis \& Integration' (EURO-BASIN, no. 264933), REPROdUCE of the ERA-NET MARIFISH (Contract ERAC-CT-2006-025989), 'Spatially resolved ecosystem models and their application to marine management' (SEAMAN SeasERA EU FP7 No. NFR:227779/E40); "SOLEMOD" (Belgian Science Policy Office, MO/36/018) and "BFishConnect" (Foundation for Scientific Research Vlaanderen, FWO (G.0702.13N). Thanks to Bee Berx for providing netcdf converters.

\section{REFERENCES}

Aksnes, D.L., Ulvestad, K.B., Balino, B., Berntsen, J., Egge, J., Svendsen, E., 1995. Ecological modelling in coastal waters: towards predictive physical-chemical-biological simulation models. Ophelia 41, 5-36.

Allain, G., Petitgas, P., Grellier, P, Lazure, P, 2003. The selection process from larval to juvenile stages of anchovy (Engraulis encrasicolus) in the Bay of Biscay investigated by Lagrangian simulations and comparative otolith growth. Fish. Oceanogr. 12: 407-418

Alvarez-Fernandez, S., Licandro, P., van Damme, C. J. G., and Hufnagl, M. 2015. Effect of zooplankton on fish larval abundance and distribution: a long-term study on North Sea herring (Clupea harengus). ICES J. Mar. Sci.: 72: 2569-2577.

Backhaus, J.O., 1985. A three-dimensional model for the simulation of shelf sea dynamics. Deutsche Hydrogr. Zeitsch. 38: 165-187.

Barthel, K., Schrum, C., Daewel, U., Årthun, M., Pushpadas, D., 2012. Resolving frontal structures: On the computational costs and pay-off using a less diffusive but computational more expensive advection scheme. Ocean Dynamics 62: 1457-1470.

Bartsch, J., Brander, K., Heath, M., Munk, P., Richardson, K., Svendsen, E., 1989. Modeling the advection of herring larvae in the North Sea. Nature 340: 632-636.

Bartsch, J, 1993. Application of a circulation and transport model system to the dispersal of herring larvae in the North Sea. Cont. Shelf Res., 13: 1335-1361. 
Beare, D, Rijnsdorp, A.D., Van Kooten, T, Fock, H, Schroeder, A, Kloppman, M, Witbaard, R, Meesters, E, Schulze, T, Blaesbjerg, M, Damm, U, Quirijns, F, 2010. Study for the Revision of the plaice box - Final Report. Report number C002/10 for the European Commission DG Maritime Affairs and Fisheries. $250 \mathrm{pp}$.

Berkenhagen, J., Döring, R., Fock H.O., Kloppmann, M.H.F., Pedersen, S.A., Schulze, T., (2010) Decision bias in marine spatial planning of offshore wind farms: Problems of singular versus cumulative assessments of economic impacts on fisheries. Mar. Policy 34: 733-736.

Beverton, R.J.H., 1995. Spatial limitation of population size; the concentration hypothesis. Neth. J. Sea Res. 34: 1-6.

Boehlert, G.W., Gill, A.B., 2010. Environmental and ecological effects of ocean renewable energy development. Oceanography 23: 68-81.

Bolle, L.J., Dickey-Collas, M., van Beek, J.K.L., Erftemeijer, P.L.A., Witte, J.IJ, van der Veer, H.W., Rijnsdorp, A.D., 2009. Variability in transport of fish eggs and larvae. III. Effects of hydrodynamics and larval behaviour on recruitment in plaice. Mar. Ecol. Progr. Ser. 390: 195211.

Booth, D.A., Meldrum, D.T., 1987. Drifting buoys in the Northeast Atlantic. J. Cons. int. Explor. Mer 43: 261-267.

Burchard, H., Bolding, K., 2002. "GETM, a general estuarine transport model: scientific documentation" Technical Report no. EUR 20253 EN, European Commission, 157 pp.

Caley, M.J., Carr, M.H., Hixon, M.A., Hughes, T.P., Jones, G.P., Menge, B.A., 1996. Recruitment and the local dynamics of open marine populations. Ann. Rev. Ecol. Syst. 27: 477-500.

Callies, U., Plüß, A., Kappenberg, J., Kapitza, H., 2011. Particle tracking in the vicinity of Helgoland, North Sea: a model comparison. Ocean Dynamics 61: 2121-2139.

Casulli, V., Stelling, G.S., 1998. Numerical simulation of 3D quasi-hydrostatic,free-surface flows. J. Hydraul. Eng. 124: 678-686.

Christensen, A., Jensen, H., Mosegaard, H., St. John, M., Schrum, C., 2008. Sandeel (Ammodytes marinus) larval transport patterns in the North Sea from an individual-based hydrodynamic egg and larval model. Can. J. Fish. Aqua. Sci. 65: 1498-1511.

Corten, A., 2013. Recruitment depressions in North Sea herring. ICES J. Mar. Sci. 70: 1-15.

Daewel, U., Peck, M.A., Kühn, W., St John, M.A., Alekseeva, I., Schrum, C., 2008. Coupling ecosystem and individual-based models to simulate the influence of environmental variability on potential growth and survival of larval sprat (Sprattus sprattus L.) in the North Sea. Fish. Oceanogr. 17: 333-351.

Daewel, U., Peck, M.A., Schrum, C., 2011a. Life history strategy and impacts of environmental variability on early life stages of two marine fishes in the North Sea: an individual-based modelling approach. Can. J. Fish. Aqua. Sci. 68: 426-443 
Daewel, U., Schrum, C., Temming, A., 2011b. Towards a more complete understanding of the life cycle of brown shrimp (Crangon crangon): modelling passive larvae and juvenile transport in combination with physically forced vertical juvenile migration. Fish. Oceanogr. 20: 479-496.

De Graaf, M., Jager, Z., Vreugdenhil, C. B., and Elorche, M., 2004. Numerical simulations of tidally cued vertical migrations of flatfish larvae in the North Sea. Estua. Coast. Shelf Sci. 59: 295-305.

Delhez, E., Damm, J.M.P., de Goede, E., de Kok, J.M., Dumas, F., Jones, J.E., Ozer, J., Pohlmann, T., Rasch, P.S., Skogen, M., Proctor, R., 2004. What can we expect from shelf seas models: the NOMADS2 Project. J. Mar. Syst. 45: 39-53.

Delpeche-Ellmann, N.C., Soomere, T., 2013. Investigating the Marine Protected Areas most at risk of current-driven pollution in the Gulf of Finland, the Baltic Sea, using a Lagrangian transport model. Mar. Poll. Bull. 67: 121-129.

Dick, S., Kleine, E., Müller-Navarra, S.H., Klein, H., Komo, H., 2001. The operational circulation model of BSH (BSHcmod)- Model description and validation. Ber. Bundesamt Seeschiffart Hydrogr. 29. $48 \mathrm{pp}$.

Dooley, H.D., 1974. Hypotheses concerning the circulation of the northern North Sea. J. Con. int. Explor. Mer 36: 54-61.

Douvere, F., Ehler, C.N., 2009. New perspectives on sea use management: Initial findings from European experience with marine spatial planning. J. Environm. Managem., 90: 77-88.

Edwards, K.P., Hare, J.A., Werner, F.E., Seim, H., 2007. Using 2-dimensional dispersal kernels to identify the dominant influences on larval dispersal on continental shelves. Mar. Ecol. Progr. Ser. 352: 77-87.

Engie, K., Klinger, T., 2007. Modeling passive dispersal through a large estuarine system to evaluate marine reserve network connections. Estua. Coasts 30: 201-213.

Fiksen, Ø., Jørgensen, C., Kristiansen, T., Vikebø, F., Huse, G., 2007. Linking behavioural ecology and oceanography: larval behaviour determines growth, mortality and dispersal. Mar. Ecol. Progr. Ser. 347: 195-205.

Fiksen, $\varnothing$., Jørgensen, C., 2011. Model of optimal behaviour in fish larvae predicts that food availability determines survival, but not growth. Mar. Ecol. Progr. Ser. 432: 207-219.

Fox, C.J., McCloghrie, P., Young, E.F., Nash, R.D.M., 2006. The importance of individual behavior for successful settlement of juvenile plaice (Pleuronectes platessa L.): a modelling and field study in the eastern Irish Sea. Fish. Oceanogr. 15: 301-313.

Gallego, A. \& Heath, M. R. 1994. The development of schooling behaviour in Atlantic herring, Clupea harengus. J. Fish Biol. 45: 569-588.

Geffen, A.J., 2009. Advances in herring biology: from simple to complex, coping with plasticity and adaptability. ICES J. Mar. Sci. 66: 1688-1695. 
Giorgi, F., Francisco, R., 2000. Evaluating uncertainties in the prediction of regional climate change. Geophy. Res. Letters 27: 1295-1298.

Hackett, B., Breivik, Ø., Wettre, C., 2006. Forecasting the drift of objects and substances in the ocean. Ocean Weather Forecasting 2006, An Integrated View of Oceanography. Chassignet, Eric P.; Verron, Jacques (Eds.) pp 507-523. ISBN 978-1-4020-4028-3

Hainbucher, D., Pohlmann, T., Backhaus, J.O., 1987. Transport of conservative passive tracers in the North Sea: First results of a circulation and transport model. Cont. Shelf Res. 7: 1161-1179.

Harding, D., Nichols, J.H., Tungate, D.S., 1978. The spawning of plaice (Pleuronectes platessa L.) in the southern North Sea and English Channel. Rapp. P.-v. Réun. Cons. int. Explor. Mer 172: 102-113.

Harms, I., Schrum, C., Hatten, K., 2005. Numerical sensitivity studies on the variability of climate relevant processes in the Barents Sea. J. Geophys. Res. 110: C06002.

Heath, M., Scott, B., Bryant, A.D., 1997. Modelling the growth of herring from four different stocks in the North Sea. J. Sea Res. 38: 413-436.

Hervouet, J.M., van Haren, L., 1996. TELEMAC2D version 3.0 Principle Note. Chatou CEDEX. Rapport EDF HE-4394052B.

Hill, A.E., James, I.D., Linden, P.F., Matthews, J.P., Prandle, D., Simpson, J.H., Gmitrowicz, E.M., Smeed, D.A., Lwiza, K.M.M., Durazo, R., Fox, A.D., Bowers, D.G., 1993. Dynamics of tidal mixing fronts in the North Sea. Phil .Trans. Royal. Soc. London A 343: 431-446.

Hill, A.E., Brown, J., Fernand, L., Holt, J., Horsburgh, K.J., Proctor, R., Raine, R., Turrell, W.R., 2008. Thermohaline circulation of shallow tidal seas. Geophys. Res. Letters 35: L11605.

Hufnagl, M., Peck, M.A., Nash, R.D.M., Pohlmann, T., Rijnsdorp, A.D., 2013. Changes in potential North Sea spawning grounds of plaice (Pleuronectes platessa L.) based on early life stage connectivity to nursery habitats. J. Sea Res. 84: 26-39.

Hufnagl, M., Temming, A., Pohlmann, T., 2014. The missing link: tidal-influenced activity a likely candidate to close the migration triangle in brown shrimp Crangon crangon (Crustacea, Decapoda). Fish. Oceanogr. 23: 242-257.

Huggett, J., Fron, P., Mullon, C., Penven, P., 2003. Modelling the transport success of anchovy Engraulis encrasicolus eggs and larvae in the southern Benguela: the effect of spatiotemporal spawning patterns. Mari. Ecol. Progr. Ser. 250: 247-262.

Huret, M., Petitgas, P., Woillez, M., 2010. Dispersal kernels and their drivers captured with a hydrodynamic model and spatial indices: A case study on anchovy (Engraulis encrasicolus) early life stages in the Bay of Biscay. Progr. Oceanogr. 87: 6-17.

Hurrel, J.W., 1995. Decadal trends in the North Atlantic Oscillation: regional temperatures and precipitation. Science 269: 676-679. 
Hurrell, J. W., Kushnir, Y., Ottersen, G. \& Visbeck, M., 2003. An Overview of the North Atlantic Oscillation, in The North Atlantic Oscillation: Climatic Significance and Environmental Impact (eds J. W. Hurrell, Y. Kushnir, G. Ottersen and M. Visbeck), American Geophysical Union, Washington, D. C.. doi: 10.1029/134GM01

ICES, 2015. Report of the Herring Assessment Working Group for the Area South of $62^{\circ} \mathrm{N}$ (HAWG). ICES CM 2015/ACOM:06.

Iles, T.C., Beverton, R.J.H., 2000. The concentration hypothesis: the statistical evidence. ICES J. Mar. Sci. 57: 216-227.

Jakobsen, T., Fogarty, M., Megrey, B., Moksness, E. (Eds.), 2009. Fish Reproductive Biology; implications for Assessment and Management. Wiley-Blackwell Ltd. ISBN 978-1-4051-2126-2. $430 \mathrm{pp}$.

Janssen, F., Schrum, C., Huebner, U. and Backhaus, J.O, 2001: Validation of a decadal simulation with a regional ocean model for North Sea and Baltic Sea. Climate Res. 18: 55-62.

Jaques, S., Kreutzkamp, P., Joseph, P., 2011. Recommendations for adaptation and development of existing and potentially new international marine spatial planning instruments. Seanergy 2020, Offshore Renewable Energy and Maritime Spatial Planning. Report IEE/09/898/SI2.558294.

Koeck, B., Gérigny, O., Durieux, E.D.H., Coudray, S., Garsi, L-H., Bisgambiglia, P-H, Galganid, F., Agostin, S., 2015. Connectivity patterns of coastal fishes following different dispersal scenarios across a transboundary marine protected area (Bonifacio strait, NW Mediterranean). Estuar. Coast. Shelf Sci. 154: 234-247.

König, P., Schrum, C., 1997. Hydrographic observations and model results from a PRISMA drift experiment April (23 to 29, 1991). Mar. Ecol. Progr. Ser. 156: 255-261.

Kühn, W., Peck, M.A., Hinrichsen, H.H., Daewel, U., Moll, A., Pohlmann, T., Stegert, C., Tamm, S., 2008. Spatial and temporal changes in the habitat suitability of the German Bight (southern North Sea) for larval sprat: An IBM approach using size-structured prey fields, J. Mar. Syst. 74: 329-342.

Lacroix, G., Maes, G.E., Bolle, L.J., Volckaert, F.A.M., 2013. Modelling dispersal dynamics of the early life stages of a marine flatfish (Solea solea L.) J. Sea Res. 84: 13-25.

Lane, A., Knight, P.J., Player, R.J., 1999. Current measurement technology for near-shore waters. Coast. Engin. 37: 343-368.

Langenberg, H., Pohlmann, T., 1994. The effect of a front on the general circulation- A Model Study of the Rhine plume area. Deutsche Hydrogr. Zeitschr. 46: 341-353

Lazure, P., Dumas, F., 2008. An external-internal mode coupling for a 3D hydrodynamical model for applications at regional scale (MARS). Adv. Water Resourc. 31, 233-250.

Lazure, P., Garnier, V., Dumas, F., Herry, C., Chifflet, M., 2009. Development of a hydrodynamic model of the Bay of Biscay. Validation of hydrology. Contin. Shelf Res. 29: 985-997. 
Lesser, G.R., Roelvink, J.A., van Kester, J.A.T.M., Stelling, G.S., 2004. Development and validation of a three-dimensional morphological model. Coast. Engin. 51: 883-915.

Leonhard, S.B., Pedersen, J., 2006. Benthic communities at Horns Rev before, during and after construction of Horns Rev offshore wind farm Vattenfall Report number: Final Report/Annual report 2005, $134 \mathrm{pp}$.

Lindeboom, H.J., Kouwenhoven, H.J., Bergman, M.J.N., Bouma, S., Brasseur, S., Daan, R., Fijn, R.C., de Haan, D., Dirksen, S., van Hal, R., Hille R., Hille Ris Lambers, R., ter Hofstede, R., Krijgsveld, K.L., Leopold, M., Scheidat, M., 2011. Short-term ecological effects of an offshore wind farm in the Dutch coastal zone. Environ. Res. Lett. 6: 035101.

Linley E.A.S., Wilding T.A., Black K., Hawkins A.J.S. and Mangi S., 2007. Review of the reef effects of offshore wind farm structures and their potential for enhancement and mitigation. Report from PML Applications Ltd and the Scottish Association for Marine Science to the Department for Business, Enterprise and Regulatory Reform (BERR), Contract No: RFCA/005/0029P

Lorkowski, I., Pätsch, J., Moll, A., Kühn, W., 2012. Interannual variability of carbon fluxes in the North Sea from 1970 to 2006-Competing effects of abiotic and biotic drivers on the gas-exchange of CO2. Estua. Coast. Shelf Sci. 100: 38-57.

Luyten, P., Jones, J.E., Proctor, R., Tabor, A., Tett, P., Wild-Allen, K., 1999. COHERENS. A Coupled Hydrodynamical-Ecological model for Regional and Shelf seas: User Documentation. MUMM Report, Management Unit of the Mathematical Models of the North Sea, Belgium. 911 p.

Michel, S., Treguier, A.-M., Vandermeirsch, F., 2009. Temperature variability in the Bay of Biscay during the past 40 years, from an in situ analysis and a 3D global simulation. Contin. Shelf Res. 29: 1070-1087.

Mittelstaedt, E., Soetje, K., Die Zirkulation in der Deutschen Bucht im August und September 1979. Deutsche Hydrogr. Zeitung 35: 59-72.

Munk, P., Kiørboe, T., 1985. Feeding behaviour and swimming activity of larval herring (Clupea harengus) in relation to density of copepod nauplii. Mar. Ecol. Progr. Ser. 24: 15-212.

Munroe, D.M., Klinck, J.M., Hofmann, E.E., Powel, E.N., 2014. A modelling study of the role of marine protected areas in metapopulation genetic connectivity in Delaware Bay oysters. Aquatic Conserv. 24: 645- 666.

Murphy, J.M., Sexton, D.M.H., Barnett, D.N., Jones, G.S., Webb, M.J., Collins, M., Stainforth, D.A., 2004. Quantification of modelling uncertainties in a large ensemble of climate change simulations. Nature 430: 768-772.

Pätsch, J., Kühn, W., 2008. Nitrogen and carbon cycling in the North Sea and exchange with the North Atlantic - a model study, Part I. Nitrogen budget and fluxes. Contin. Shelf Res. 28: 767-787.

Pastoors, M.A., Rijnsdorp, A.D., van Beek, F.A.. 2000 Effects of a partially closed area in the North Sea ("plaice box") on stock development of plaice. ICES J. Mar. Sci. 57: 1014-1022. 
Payne, M.R., Hatfield, E.M.C., Dickey-Collas, M., Falkenhaug, T., Gallego, A., Gröger, J., Licandro, P., Llope, M., Munk, P., Röckmann, C., Schmidt, J.O., Nash, R.D.M., 2009. Recruitment in a changing environment: the 2000s North Sea herring recruitment failure. ICES J. Mar. Sci. 66: 272-277.

Peck, M.A., Hufnagl, M., 2012. Can IBMs tell us why most larvae die in the sea? Model sensitivities and scenarios reveal research needs. J. Mar. Syst. 93: 77-93.

Pohlmann, T., 1996. Predicting the thermocline in a circulation model of the North Sea -Part I: Model description, calibration and verification. Contin. Shelf Res. 16: 131-146.

Pohlmann, T., 2006. A meso-scale model of the central and southern North Sea: Consequences of an improved resolution. Contin. Shelf Res. 26: 2367-2385.

Postma, L., van Beek, J.K.L., van den Boogaard, H.F.P., Stelling, G.S., 2013. Consistent and efficient particle tracking on curvilinear grids for environmental problems. Intern. J. Numerical Meth. Fluids 71: 1226-1237.

Proctor, R. (Ed.), 1997. EC concerted action (MAS2-CT94-0105) in the field of numerical modelling of marine systems, NOMADS-North Sea Model Advection Dispersion Study, Final Report, POL International Document No. 108, 55 pp

Savina, M., Lacroix, G., Ruddick, K., 2010. Modelling the transport of common sole larvae in the southern North Sea: influence of hydrodynamics and larval vertical movements. J. Mar. Syst. 81: 86-98.

Schmidt, J.O., van Damme, C.J.G., Rockmann, C., Dickey-Collas, M., 2009. Recolonisation of spawning grounds in a recovering fish stock: recent changes in North Sea herring. Scientia Marina, 73: 153-157.

Schrum, C., Backhaus, J.O, 1999. Sensitivity of atmosphere ocean heat exchange and heat content in the North Sea and Baltic Sea. Tellus, 51A: 526-549.

Shanks, A.L., Pelagic larval duration and dispersal distance revisited. Biol. Bull. 216: 373-385.

Siegel, D.A., Mitarai, S., Costello, C.J., Gaines, S.D., Kendall, B.E., Warner, R.R., Winters, K.B., 2008. The stochastic nature of larval connectivity among nearshore marine populations. PNAS 105: 8974-8979.

Siegismund, F., Schrum, C., 2001. Decadal changes in the wind forcing over the North Sea. Climate Res. 18: 39-45.

Skogen, M.D., Søiland, H., 1998. A user's guide to NORWECOM v2.0. The NORWegian ECOlogical Model system. Fisk. Havet, No. 18:42pp.

Skogen, M.D., Svendsen, E., Berntsen, J., Aksnes, D., Ulvestad, K.B., 1995. Modelling the primary production in the North Sea using a coupled 3 dimensional physical chemical biological ocean model. Estuar. Coast. Shelf Sci. 41: 545-565. 
Talbot, J.W., 1977. The dispersal of plaice eggs and larvae in the Southern Bight of the North Sea. J. Cons. Int. Explor. Mer 37: 221-248.

Taylor, N., Fox, C.J., Bolle, L.J., Dickey-Collas, M., et al., 2007. Results of the spring 2004 North Sea ichthyoplankton surveys. ICES Coop Res Rep No. 285. ICES, Copenhagen.

Tiessen, M.C.H., Fernard, L., Gerkema, T., van der Molen, J., Ruardij, P., van der Veer, H.W., 2014. Numerical modelling of physical processes governing larval transport in the southern North Sea. Ocean Science 10: 357-376.

Ulrich, C., Boje, J., Cardinale, M., Gatti, P., LeBras, Q., Andersen, M., Hemmer-Hansen, J., Hintzen, N.T., Jacobsen, J.B., Jonsson, P., Miller, D.C.M., Nielsen, E.E., Rijnsdorp, A.D., Sköld, M., Svedäng, H., Wennhage, H., 2013. Variability and connectivity of plaice populations from the Eastern North Sea to the Western Baltic Sea, and implications for assessment and management. J. Sea Res. 84: 40-48.

van der Molen, J., Rogers, S.I., Ellis, J.R., Fox, C.J., McCloghrie, P., 2007. Dispersal patterns of the eggs and larvae of spring-spawning fish in the Irish Sea, UK. J. Sea Res. 58: 313-330.

van der Veer, H.W., 1986. Immigration, settlement and density-dependent mortality of a larval and early post-larval 0-group plaice (Pleuronectes platessa) population in the western Dutch Wadden Sea. Mar. Ecol. Progr. Ser. 29: 223-236.

van der Veer, H.W., Ruardy, P., van den Berg, A.J., Ridderinkhof, H. (1998). Impact of interannual variability in hydrodynamic circulation on egg and larval transport of plaice Pleuronectes platessa L. in the southern North Sea. J. Sea Res. 39, 29-40.

van Ulden, A.P., van Oldenborgh, G.J., 2006. Large-scale atmospheric circulation biases and changes in global climate model simulations and their importance for climate change in Central Europe. Atmosph. Chem. Phys., 6: 863-881.

Vikebø, F., Jørgensen, C., Kristiansen, T., Fiksen, Ø., 2007. Drift, growth, and survival of larval Northeast Arctic cod with simple rules of behaviour. Mar. Ecol. Progr. Ser. 347: 207-219.

Visser, A., 1997. Using random walk models to simulate the vertical distribution of particles in a turbulent water column. Mar. Ecol. Progr. Ser. 158: 275-281.

Wang, G., 2005. Agricultural drought in a future climate: results from 15 global climate models participating in the IPCC 4th assessment. Climate Dynam. 25: 739-753.

Zijlstra, J.J., 1972. On the importance of the Wadden Sea as a nursery area in relation to the conservation of the southern North Sea fishery resources. Symp. Zool. Soc. London 29: 233258. 


\section{FIGURES}

Figure 1: Left: Spawning areas of plaice (yellow), sole (red), overlapping areas (orange) and herring (green line) in the southern North Sea. Black lines indicate transects T1T7 defined in Table 2. Right: Location of the plaice box (red) and planned, authorized or fully commissioned wind park areas (blue) in the North Sea.

Figure 2: Domains of the ocean circulation models (OCMs) used in this study. For more details of nested models, see Table 1 and supplementary. Insert shows an overlay of the different domains. Darker areas were covered by more models than light grey areas.

Figure 3: Combined particle distributions from all models used. Panels were sorted by year (from left to right) and scenario (top to bottom). Drifters of all vertical layers were summed up for any $0.1^{\circ} \times 0.1^{\circ}$ grid pixel. Panel (b) HeT6-1996, (e) HeT6-1998, (h) HeT6-2002, (k) HeT6-2005, (a) PIT2-1996, (d) PIT2-1998, (g) PIT2-2002, (c) SoT7-2005, (f) SoT7-1996, (i) SoT7-1998, (I) SoT7-2002, (I) PIT2-2005 Yellow areas refer to areas of highest particle densities dark blue to areas where only few particles ended. White areas were not reached by any particle. Yellow-white lines indicate transects from which particles were started in the different scenarios. Red areas indicate wind parks and the plaice box (see also Figure 1). White dots with red and black margins represent end location of the center of mass.

Figure 4: Start and mean end particle position obtained from all models used for the scenario PIT2 (Plaice Transect 2) and the years 1996, 1998, 2002 and 2005. The graphs show for each model the center of gravity of all particles. The black dashed line indicates the start transect.

Figure 5: Start and mean end particle position obtained from all models used for the scenario HeT6 (Herring Transect 6) and the years 1996, 1998, 2002 and 2005. The graphs show for each model the center of gravity of all particles. The black dashed line indicates the start transect.

Figure 6: Start and mean end particle position obtained from all models used for the scenario SoT7 (Sole Transect 7) and the years 1996, 1998, 2002 and 2005. The graphs show for each model the center of gravity of all particles. The black dashed line indicates the start transect.

Figure 7: Boxplots based on the 50000 particles used per scenario. Shown are final longitude (upper row), final latitude (middle row) and experienced temperature (lower row). Three selected scenarios were presented: PIT2 (Eastern English 
Channel plaice, left column), HeT6 (Banks herring, middle column) and SoT7 (German Bight sole, right panel). Boxplots are grouped (separated by the vertical black lines) by the years 1996, 1998, 2002 and 2005. Horizontal black lines in the higher two rows indicate the mean start location for the scenario. Long red horizontal lines indicate the overall final median position (all particles of all models) for the respective scenario and year. Boxes of the boxplots were defined as the 5, 25, 75 and 95 percentiles, outliers were not shown. The acronyms refer to the used models: BSP: BSHcmod-PELETS, DEL: DELFT3D, ECH: ECOHAM, ECS: ECOSMO, GET: GETM, HAP: HAMSOM-PELETS, H20: HAMSOM2Okm, H03: HAMSOM3km, LAR: LARVAE\&CO, MAR: MARS3D, NOR: NORWECOM, TEP: TELEMAC-PELETS, TRP: TRIM-PELETS.

Figure 8: Deviation of temperatures (experienced by particles during the drift), end longitude and latitude by scenario and model in relation to the ensemble median. Boxplots were based on all scenarios simulated with one model.

Figure 9: Dendrogram (Ward analysis based on Euclidian distances) comparing the relation between models based on the 12 kernel parameters obtained from each scenario.

Figure 10: Fraction of particles representing sole (left) and plaice (right column) that ended inside the plaice box at the end of each scenario. Each color represents one model, model abbreviations as in Figure 7. Boxplots were determined based on all models used in the respective year and scenario. Crosses indicate missing values (cases where the model could not be applied).

Figure 11: Fraction of particles representing herring that ended inside a wind park at the end of each scenario. Each color represents one model, model abbreviations as in Figure 7. Boxplots were determined based on all models used in the respective year and scenario. Crosses indicate missing values (cases where the model could not be applied). 
Figure 1

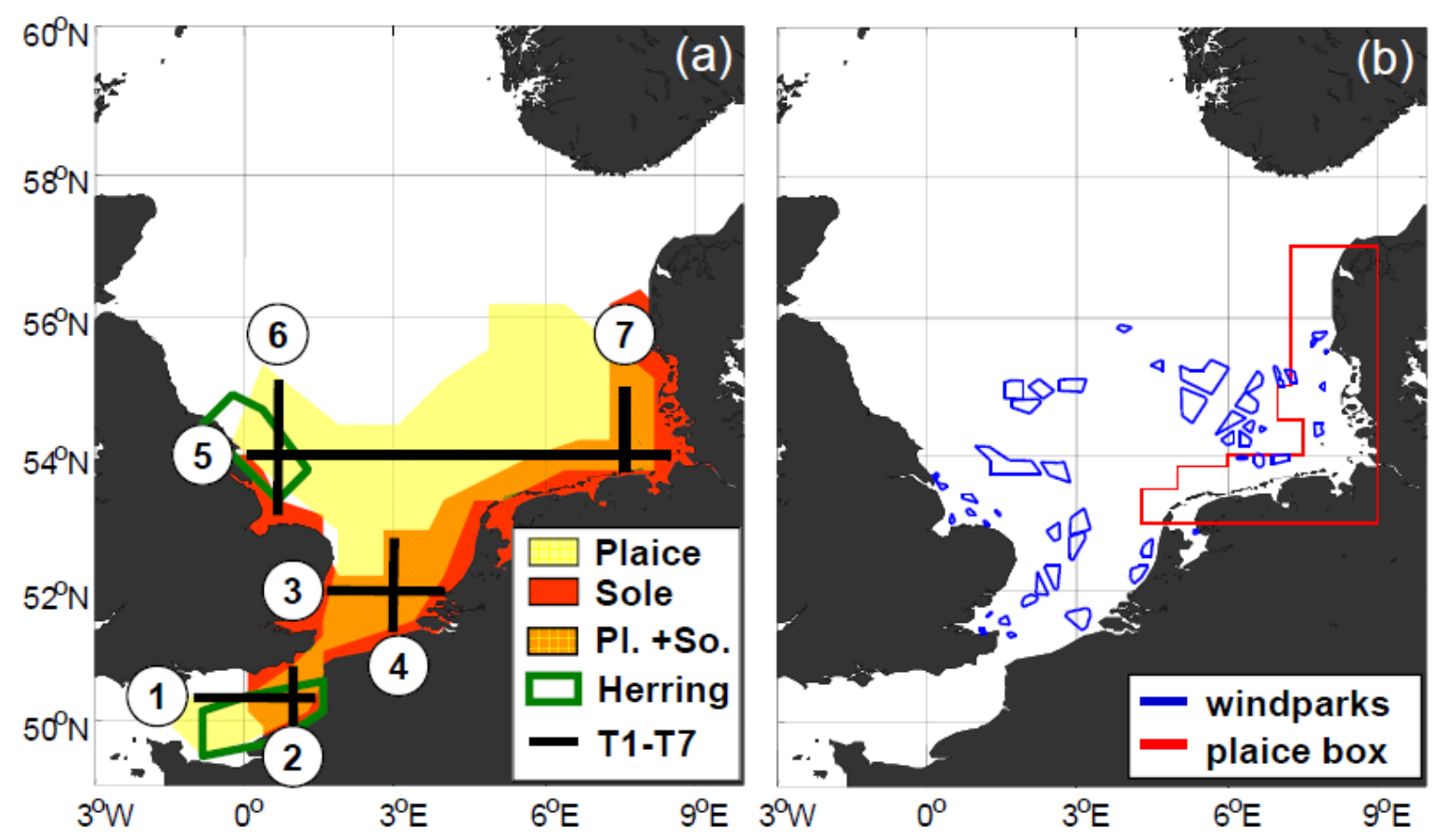


Figure 2

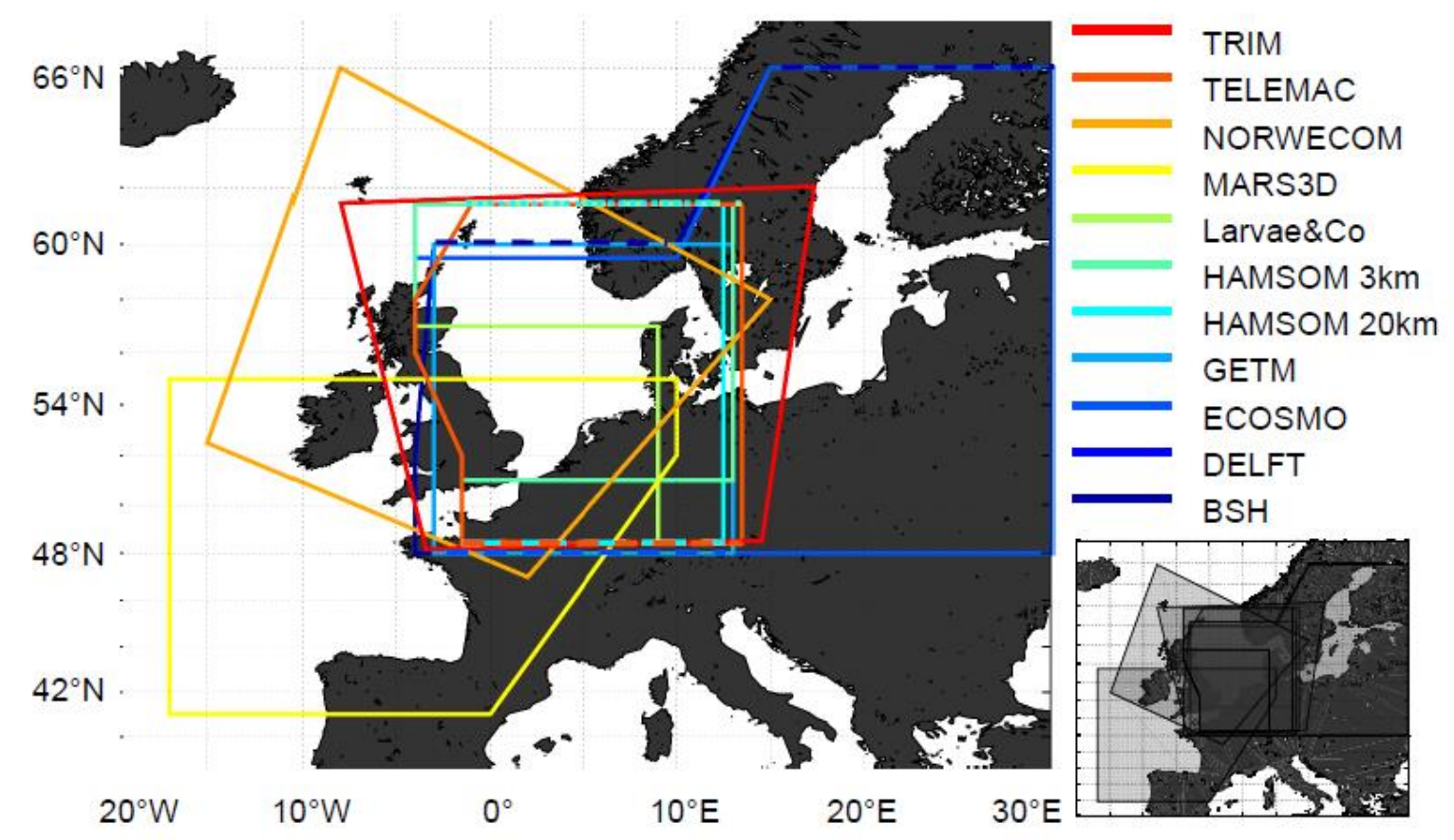




\section{ACCEPTED MANUSCRIPT \\ 40}

Figure 3
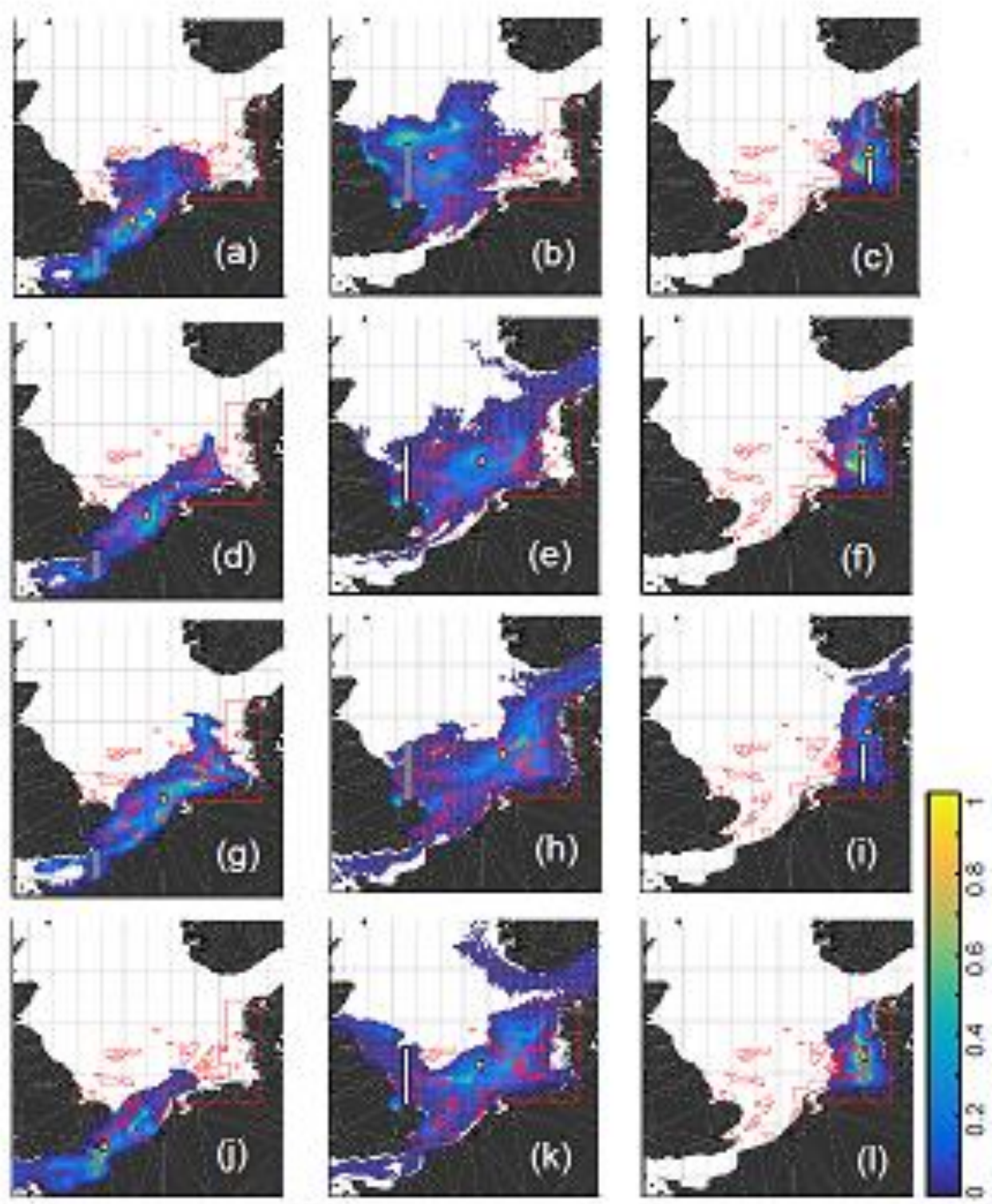
Figure 4

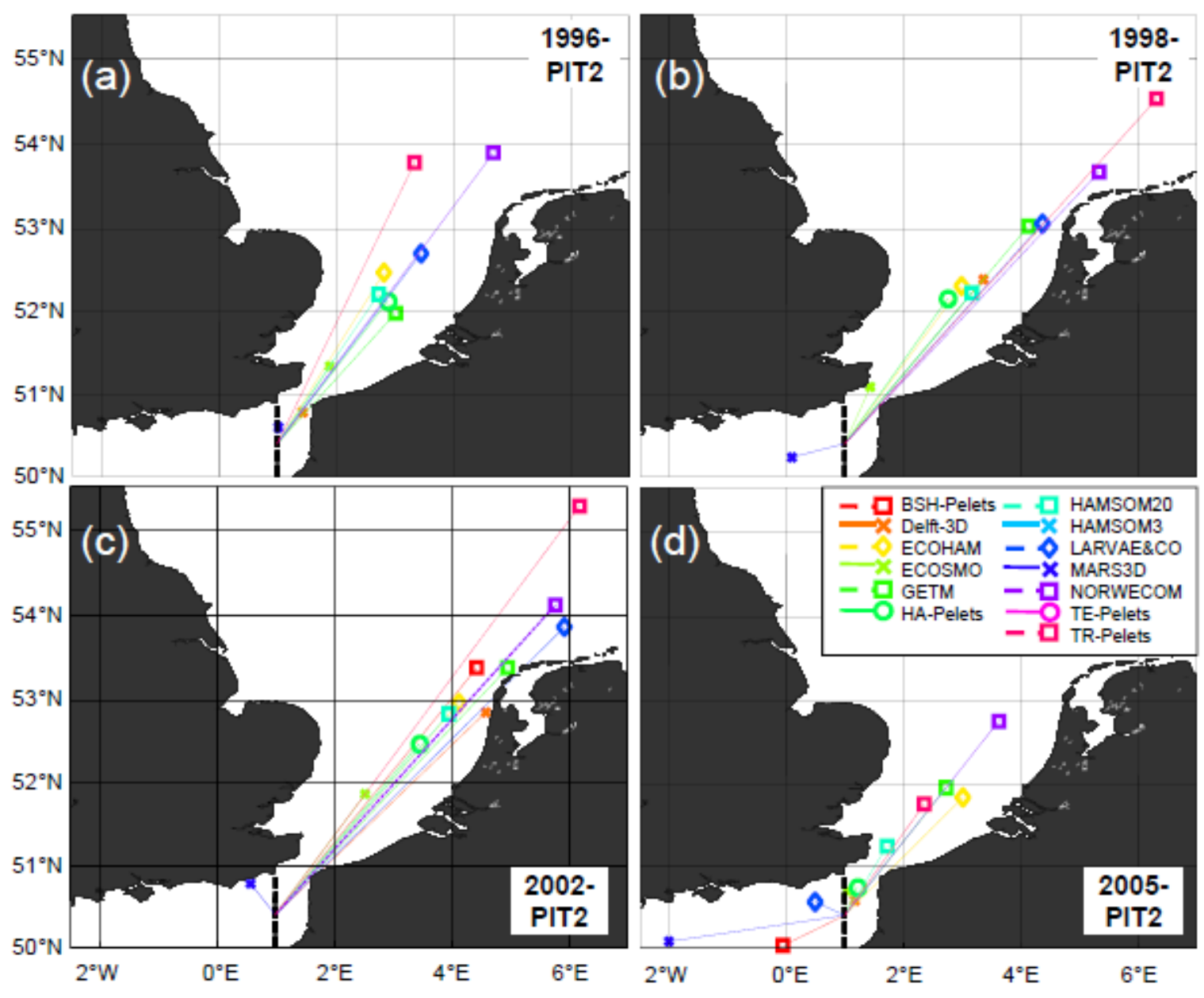


Figure 5

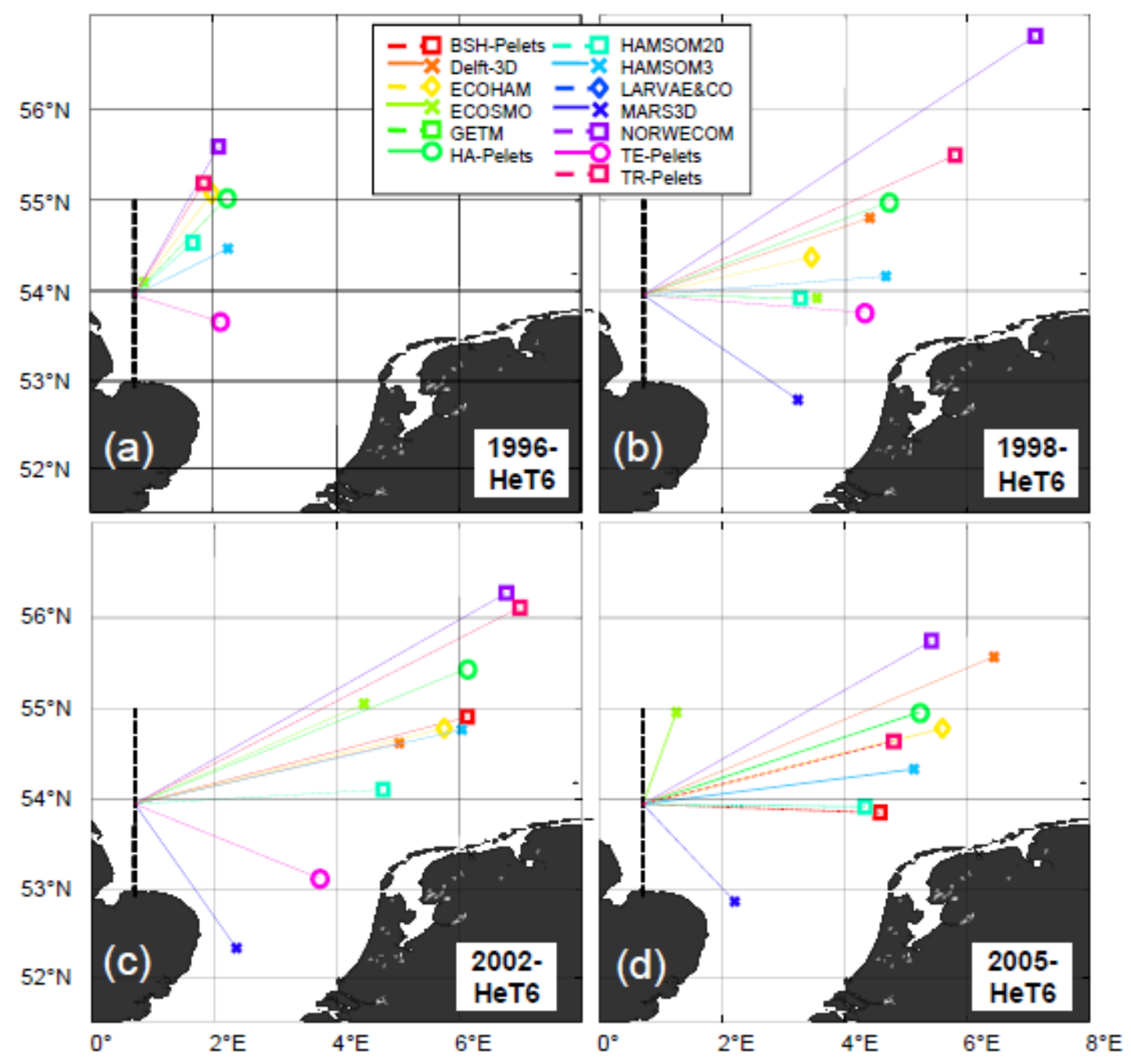


Figure 6

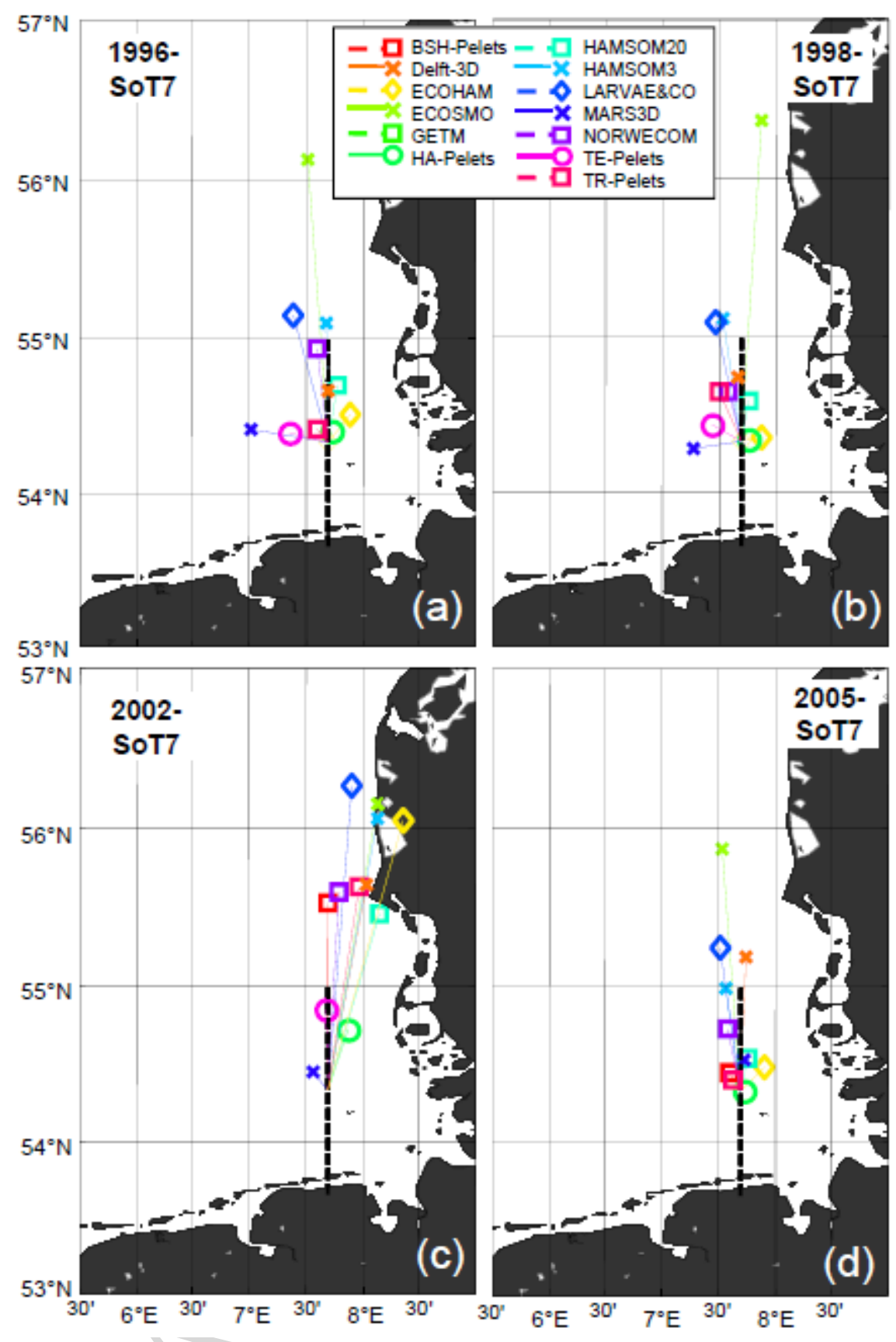


PIT2

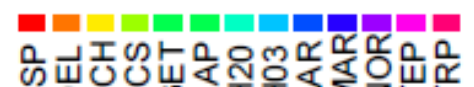

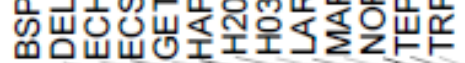
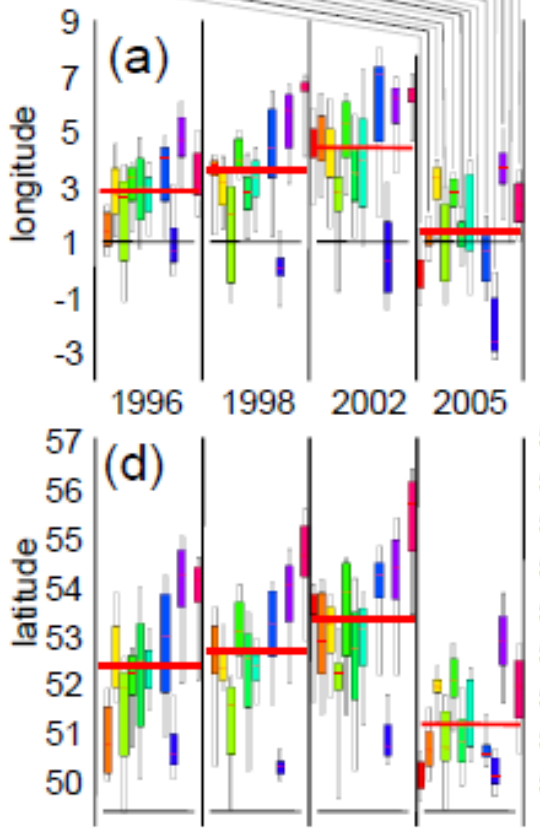

$\begin{array}{lllll}9 & 1996 \quad 1998 \quad 2002 \quad 2005\end{array}$

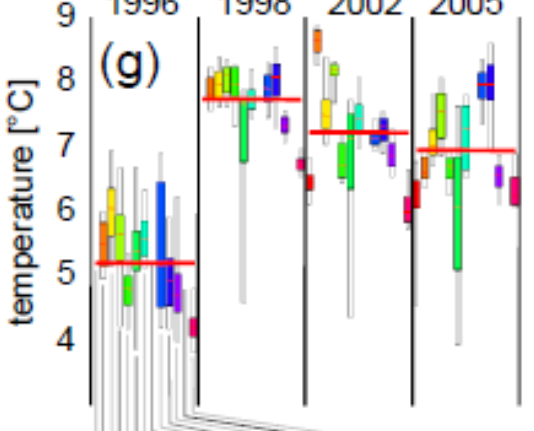

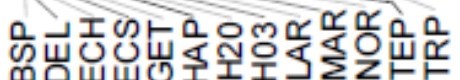

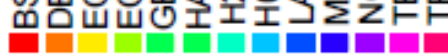

PIT2
HeT6

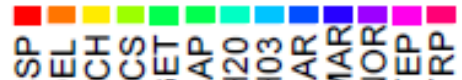

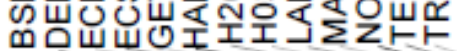

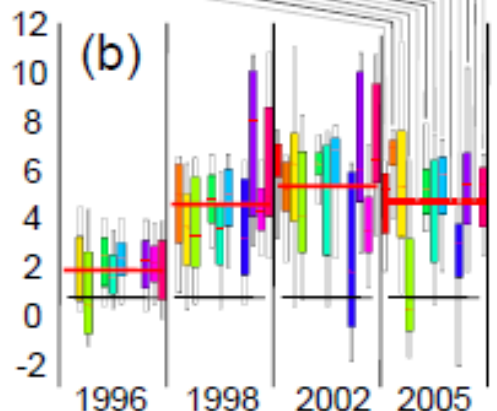

$\begin{array}{llll}1996 & 1998 \quad 2002 \quad 2005\end{array}$
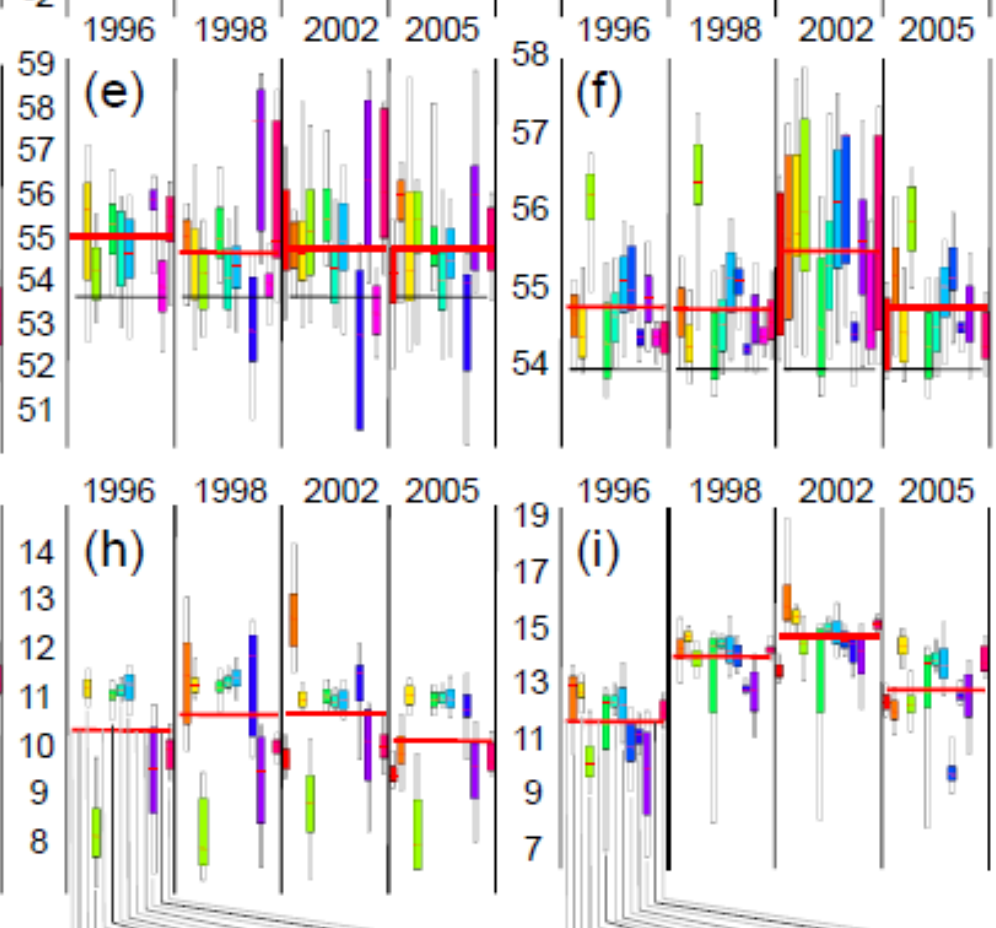

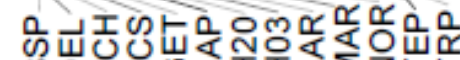

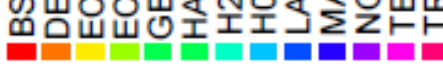
HeT6
Figure 7 SoT7

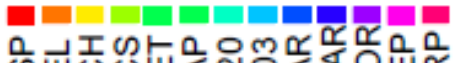

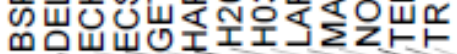

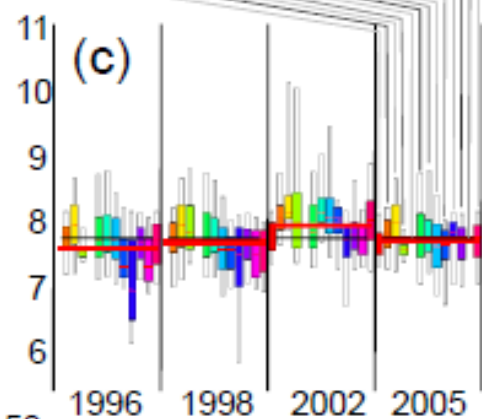

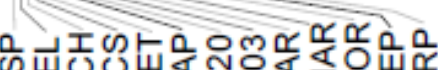

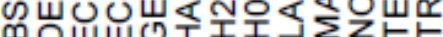
๓口யயலエII」ZZトト SoT7 


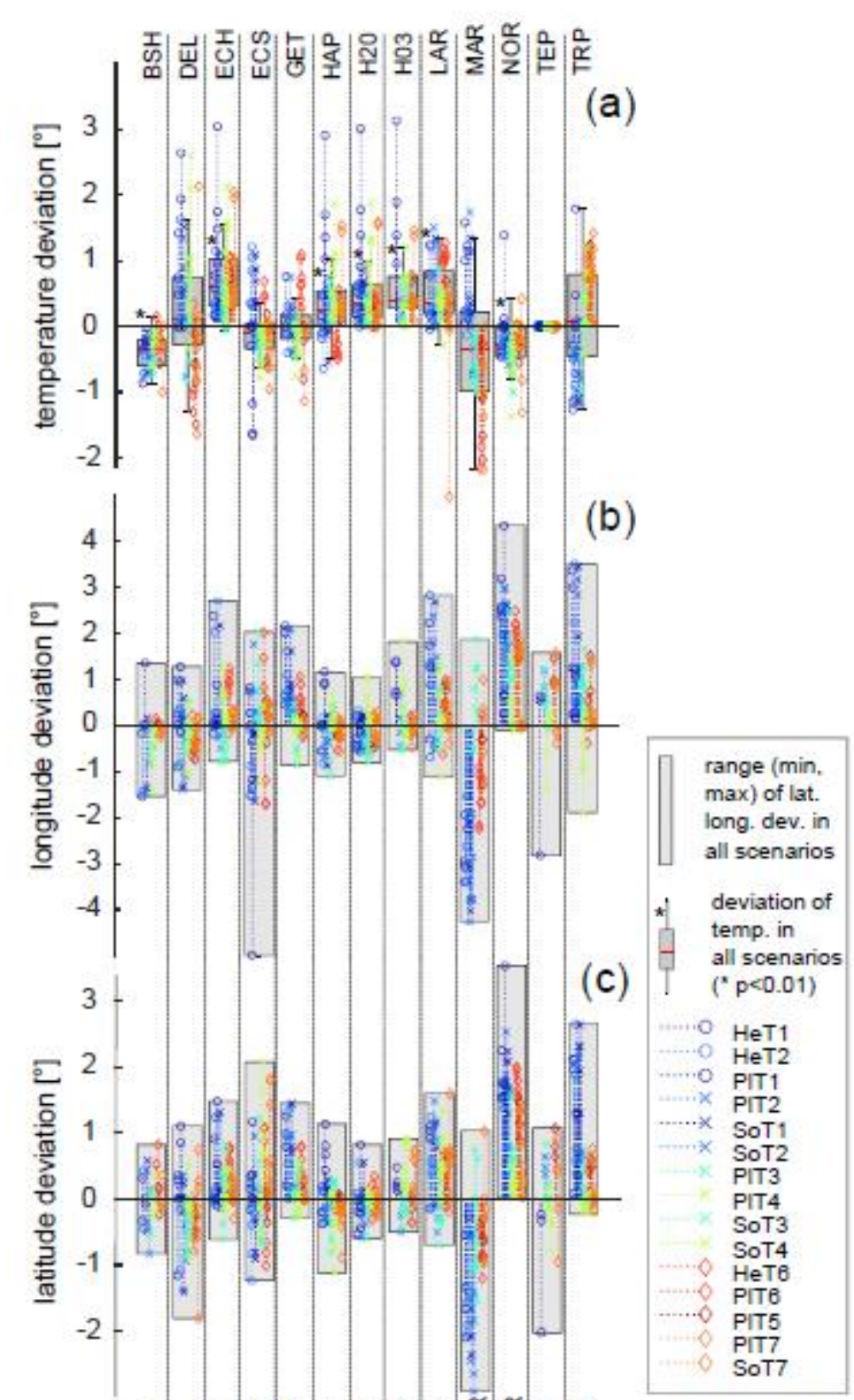

Figure 8

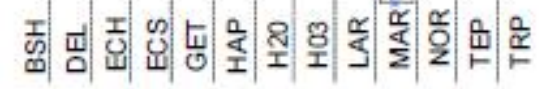


Figure 9

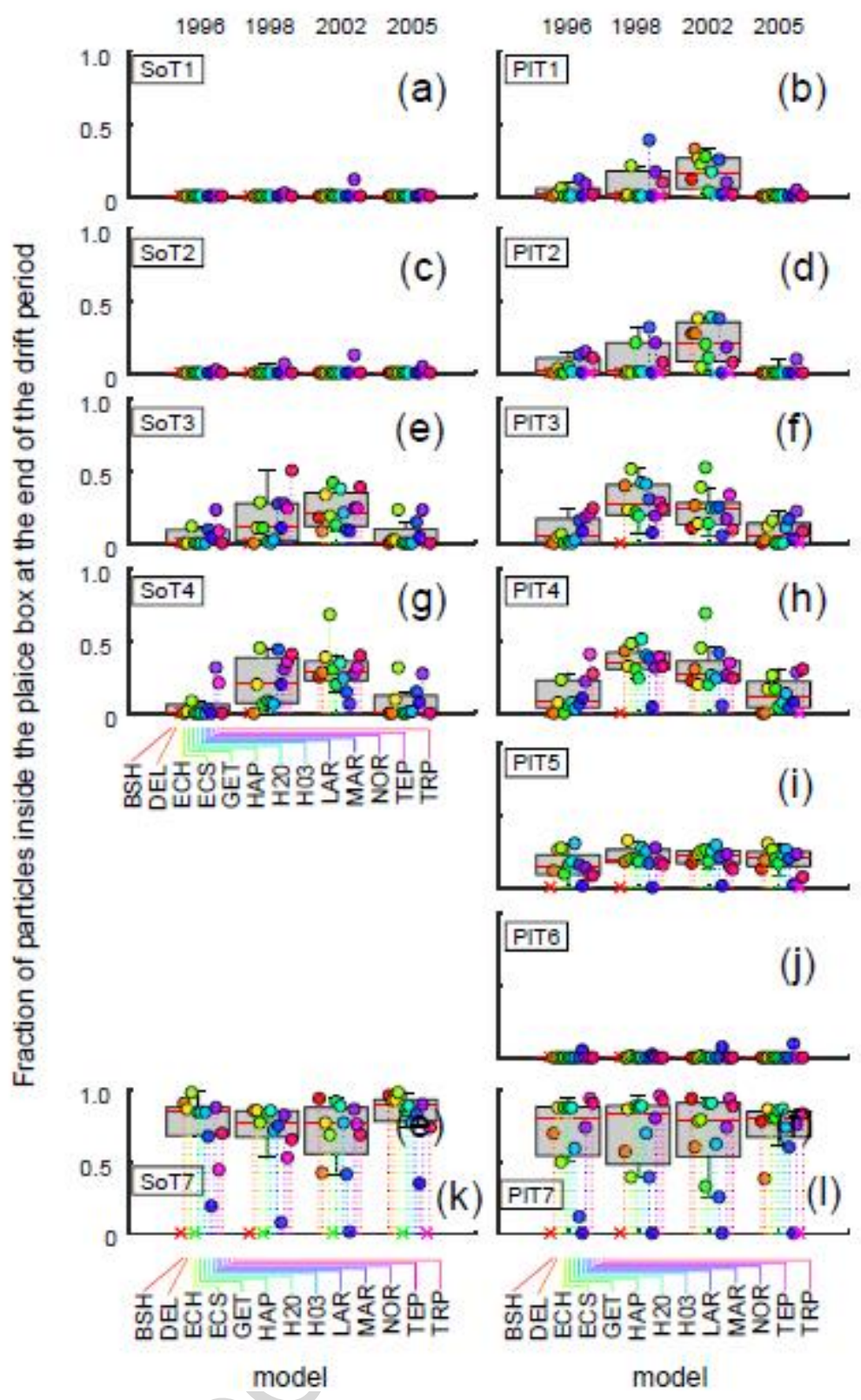


Figure 10

(a)

(b)

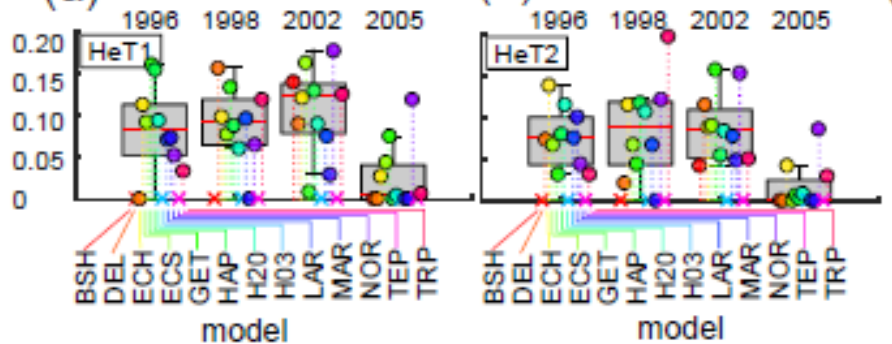

(c)

$\begin{array}{llll}1996 & 1998 \quad 2002 \quad 2005\end{array}$ HeT6

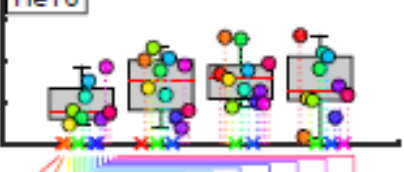

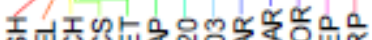
model model 


\section{TABLES}

Table 1: Overview of general model settings. Columns from left to right: 1. Name of the model system. PELETS is the name of the Lagrangian Drift Module (LDM) and therefore appears more often. 2. 3D or 2D approach of the LDMs 3. Settings and forcing at the open boundaries 4. Description whether the LDM is using output of the Ocean Circulation Model (OCM) or whether it was coupled on-line. 4. Horizontal resolution of the OCMs. Some models use geographic coordinates, some have curvilinear grids and some are nested. As a general and easear to handle resolution unit, $\mathrm{km}$ were indicated, however, these are often just average values. 5. Vertical resolution. 6. Temporal resolution of the LDMs. 7. Inclusion of horizontal diffusion and if so which value. 8. Key references for the OCMs and the LDMs describing the structure and the used settings in detail. TE: TELEMAC, TR: TRIM, NO: NORWECOM, HA: HAMSOM, BSH: BSHcmod.

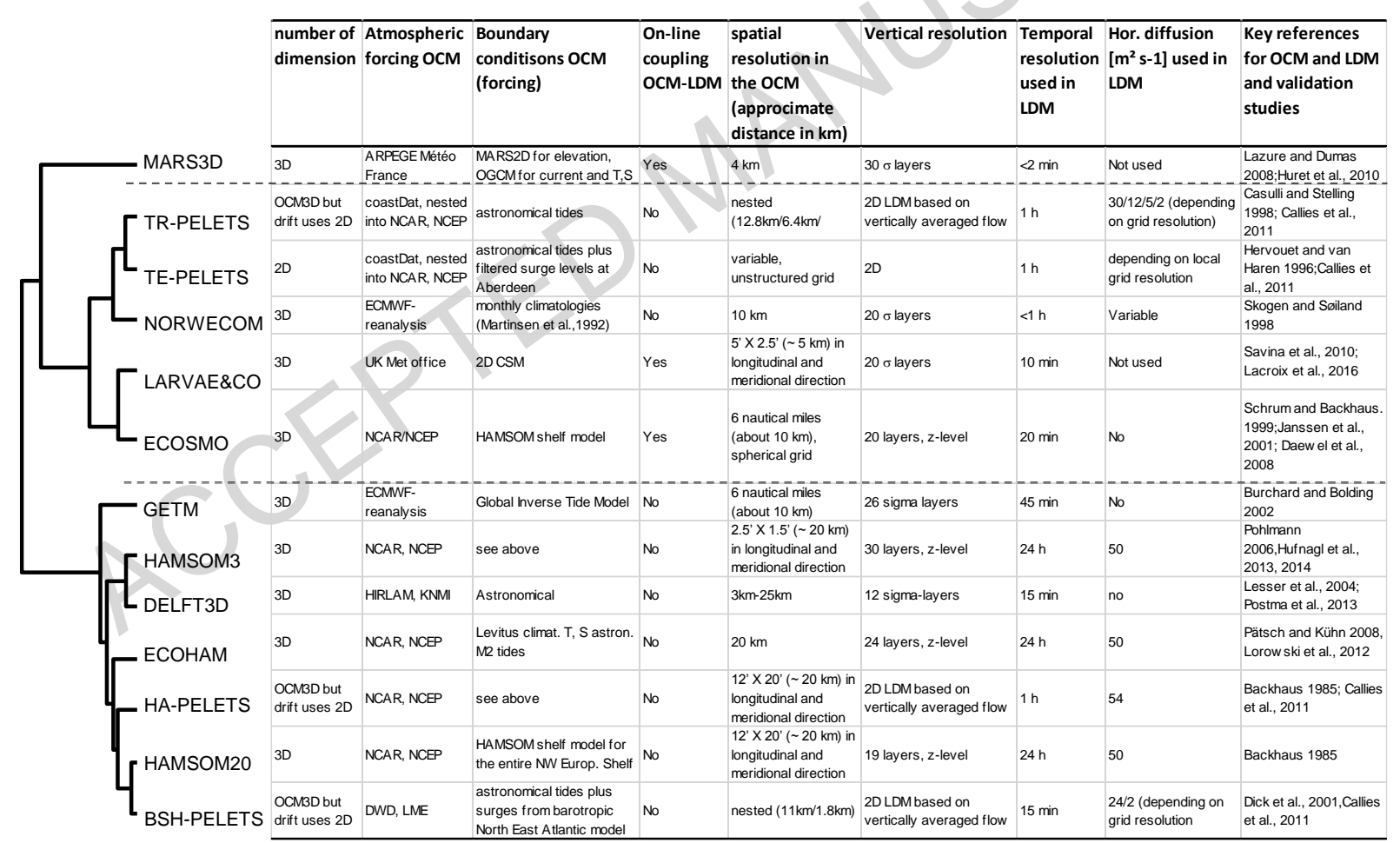


Table 2: Start and end points of transects tracer particles were initialized on. The acronyms Fr, UK, B and Ger represent the first "dry" (land) point in each hydrodynamic model at the French, United Kingdom, Belgian and German coast, respectively.

\begin{tabular}{lll}
\hline Transect & Start & End \\
\hline T1: & $1.0^{\circ} \mathrm{W} / 50.4^{\circ} \mathrm{N}$ & $\mathrm{Fr} / 50.4^{\circ} \mathrm{N}$ \\
T2: & $1.0^{\circ} \mathrm{E} / \mathrm{Fr}$ & $1.0^{\circ} \mathrm{E} / \mathrm{UK}$ \\
T3: & $\mathrm{UK} / 52.0^{\circ} \mathrm{N}$ & $\mathrm{NI} / 52.0^{\circ} \mathrm{N}$ \\
T4: & $3.0^{\circ} \mathrm{E} / \mathrm{B}$ & $3.0^{\circ} \mathrm{E} / 52.5^{\circ} \mathrm{N}$ \\
$\mathrm{T} 5:$ & $\mathrm{UK} / 54.0^{\circ} \mathrm{N}$ & $\mathrm{Ger} / 54.0^{\circ} \mathrm{N}$ \\
T6: & $0.7^{\circ} \mathrm{E} / \mathrm{UK}$ & $0.7^{\circ} \mathrm{E} / 55.0^{\circ} \mathrm{N}$ \\
T7: & $7.7^{\circ} \mathrm{E} / \mathrm{Ger}$ & $7.7^{\circ} \mathrm{E} / 55.0^{\circ} \mathrm{N}$ \\
\hline
\end{tabular}


Table 3: Scenario acronyms and species which the scenario is based. T1-T7 represent the different transects used in the scenario (Table 2, Figure 2). the last for columns are the start and end dates (calendar days and dates) used in the different scenarios mimicking the different species (herring, plaice, sole).

\begin{tabular}{|c|c|c|c|c|c|c|}
\hline Scenario & Species & Transect & Start day & Start Date & End day & End Date \\
\hline HeT6 & Herring & T6 & $\begin{array}{l}257 \text { (year } \\
\text { before) }\end{array}$ & Sep $15^{\text {th }}$ & 37 & Feb $7^{\text {th }}$ \\
\hline HeT1 & Herring & $\mathrm{T} 1$ & 1 & $\operatorname{Jan} 1^{\text {st }}$ & 75 & $\operatorname{Mar} 17^{\text {th }}$ \\
\hline НеТ2 & Herring & $\mathrm{T} 2$ & 1 & $\operatorname{Jan} 1^{\text {st }}$ & 75 & $\operatorname{Mar} 17^{\text {th }}$ \\
\hline PIT1 & Plaice & $\mathrm{T} 1$ & 1 & $\operatorname{Jan} 1^{\mathrm{st}}$ & 90 & Apr $1^{\text {st }}$ \\
\hline PIT2 & Plaice & T2 & 1 & $\operatorname{Jan} 1^{\text {st }}$ & 90 & Apr $1^{\text {st }}$ \\
\hline PIT3 & Plaice & T3 & 45 & Feb15 ${ }^{\text {th }}$ & 135 & May $16^{\text {th }}$ \\
\hline PIT4 & Plaice & $\mathrm{T} 4$ & 45 & Feb15 ${ }^{\text {th }}$ & 135 & May $16^{\text {th }}$ \\
\hline PIT5 & Plaice & T5 & 73 & $\operatorname{Mar} 15^{\text {th }}$ & 163 & Jun $13^{\text {th }}$ \\
\hline PIT6 & Plaice & T6 & 73 & $\operatorname{Mar} 15^{\text {th }}$ & 163 & Jun $13^{\text {th }}$ \\
\hline PIT7 & Plaice & $\mathrm{T} 7$ & 73 & $\operatorname{Mar} 15^{\text {th }}$ & 163 & Jun $13^{\text {th }}$ \\
\hline SoT1 & Sole & $\mathrm{T} 1$ & 104 & Apr $15^{\text {th }}$ & 164 & Jun $14^{\text {th }}$ \\
\hline SoT2 & Sole & $\mathrm{T} 2$ & 104 & Apr $15^{\text {th }}$ & 164 & Jun $14^{\text {th }}$ \\
\hline SoT3 & Sole & T3 & 119 & Apr $30^{\text {th }}$ & 179 & Jun $29^{\text {th }}$ \\
\hline SoT4 & Sole & $\mathrm{T} 4$ & 119 & Apr $30^{\text {th }}$ & 179 & Jun $29^{\text {th }}$ \\
\hline SoT7 & Sole & $\mathrm{T} 7$ & 134 & May $15^{\text {th }}$ & 194 & Jul $7^{\text {th }}$ \\
\hline
\end{tabular}

